\title{
The Rise and Fall of Small Worlds: Exploring the Dynamics of Social Structure
}

\section{Citation}

Gulati, Ranjay, Maxim Sytch, and Adam Tatarynowicz. "The Rise and Fall of Small Worlds:

Exploring the Dynamics of Social Structure." Organization Science (March-April 2012): 449-471.

\section{Published Version}

http://orgsci.journal.informs.org/content/23/2/449.abstract

\section{Permanent link}

http://nrs.harvard.edu/urn-3:HUL.InstRepos:10996798

\section{Terms of Use}

This article was downloaded from Harvard University's DASH repository, and is made available under the terms and conditions applicable to Open Access Policy Articles, as set forth at http:// nrs.harvard.edu/urn-3:HUL.InstRepos:dash.current.terms-of-use\#OAP

\section{Share Your Story}

The Harvard community has made this article openly available.

Please share how this access benefits you. Submit a story.

\section{Accessibility}




\title{
The Rise and Fall of Small Worlds: Exploring the Dynamics of Social Structure
}

\author{
Ranjay Gulati \\ Harvard Business School \\ Harvard University \\ Morgan Hall, Soldiers Field \\ Boston, MA 02163 \\ Ph: 617.495.6327 Fax: 617.496.6568 \\ rgulati@bbs.edu \\ Maxim Sytch \\ Ross School of Business \\ University of Michigan \\ 701 Tappan St. \\ Ann Arbor, MI 48109 \\ Ph: 734.763.6822 Fax: 734.764.2555 \\ msytch@bus.umich.edu \\ Adam Tatarynowicz \\ Department of Organization and Strategy \\ Tilburg University \\ P.O. Box 90153 \\ NL-5000 LE Tilburg \\ Ph: +31.13.466.4050 Fax: +31.13.466.8354 \\ a.tatarynowic?@wt.nl
}

- All authors contributed equally. We thank Roger Guimera, Dovev Lavie, Martin Ruef, and Ithai Stern for helpful comments on the paper. 


\title{
The Rise and Fall of Small Worlds: Exploring the Dynamics of Social Structure
}

\begin{abstract}
This paper explores the interplay between social structure and economic action by examining some of the evolutionary dynamics of an emergent network that coalesces into a small-world system. The study highlights the small-world system's evolutionary dynamics at both the macro level of the network and the micro level of an individual actor. This dual analytical lens helps establish that, in competitive and information-intensive settings, a small-world system could be a highly dynamic structure that follows an inverted U-shaped evolutionary pattern, wherein an increase in the smallworldliness of the system is followed by its later decline due to three factors: (1) the recursive relationship between the evolving social structure and individual actors' formation of bridging ties, which eventually homogenizes the information space and decreases actors' propensity to form bridging ties, creating a globally separated network; (2) self-containment of the small-world network, or increasing homogenization of the social system, which makes the small world less accepting of and less attractive to new actors, thereby limiting formation of bridging ties to outside clusters; and (3) fragmentation of the small-world network, or the small-world system's inability to retain current clusters. The study uses data on interorganizational tie formation in the global computer industry in the period from 1996 to 2005 to test the hypothesized relationships.
\end{abstract}

\section{INTRODUCTION}

Studies in organization theory and sociology have long recognized the importance of social structure in shaping the behaviors and outcomes of social actors (e.g., Baker 1984; Granovetter 1985). It is now well established that the concrete patterns of social interactions in which actors are embedded have an impact on the actors' behaviors and outcomes in a variety of contexts (Ahuja 2000; Fernandez and Fernandez-Mateo 2006; Galaskiewicz et al. 2006; Gulati 1999). As a consequence, actors' embeddedness in the social structure and the characteristics of the social structure itself have become perennial subjects of organizational and sociological research. In recent years, more researchers have come to focus on one particular class of social structure: smallworld systems.

Rooted in the early conceptualizations of Frigyes Karinthy (1929) and the six-degrees-of-separation experiment conducted by Stanley Milgram (1967), ideas related to small-world systems have received renewed scholarly attention in the wake of recent advances in analytical formulations of this phenomenon (Watts and Strogatz 1998). In essence, the presence of small-world architecture in a social system endows members of even relatively sparse networks with a unique capacity for connectivity and coordinated action. Because small worlds display the combination of high interconnectivity among actors' immediate contacts and the presence of some connections spanning those clusters of high connectivity, social actors in these systems are much more able to reach other actors in the social space through a relatively small number of intermediaries. 
A number of factors have led to the growing scholarly attention to small-world systems. First, small worlds have been found to characterize a wide variety of social settings, ranging from patterns of scientific collaboration (Newman 2001) to corporate board interlocks (Davis et al. 2003). Second, not only are small worlds now considered ubiquitous social structures, but - in line with extant findings that social structure shapes economic action - they are also increasingly recognized as robust drivers of individual and collective action (e.g., Uzzi and Spiro 2005). However, despite the ubiquity of small-world systems and the growing body of research on their importance for social action and outcomes, there is a dearth of knowledge regarding the evolutionary dynamics underlying their development and transformation.

In contrast to recent research that has analyzed small-world systems at a macro-social level and focused primarily on these networks' macro properties, such as clustering coefficient and average path length (Davis et al. 2003; Rosenkopf and Schilling 2007; Uzzi and Spiro 2005), our study focuses on the evolution of small worlds and adopts a multilevel dynamic approach. Consistent with previous applications of this approach in social and economic sciences (Doreian and Stokman 1997; Gulati 1995; Gulati and Gargiulo 1999; Jackson and Rogers 2007), this stance allows us to consider the evolutionary dynamics of small worlds at two distinct levels: the macro-social level or network level of global properties of small worlds and the micro-social level or actor level of behavioral trends underlying these global features. The macro- or network-level lens enables us to better understand how the micro-level actions of social actors are guided by the global properties of an evolving smallworld system. Analyzing micro-level behavioral trends, in turn, focuses on the actions of individual social actors, which result in the formation of social ties and agglomerate into the macro-level social structures of small worlds. This multilevel approach allows us to elucidate the evolution of small-world networks and to explore one of their qualities that has not yet been considered, namely, their highly dynamic nature. Specifically, we show that in competitive and information-intensive social systems, a small-world system may follow an inverted U-shaped evolutionary pattern, wherein the formation stage is marked by an increase in small-world properties, but is eventually followed by a period of rapid decline in small-world topology.

Conceiving of small-world structures as dynamic social systems that follow intricate evolutionary trajectories is important for several reasons. First, since there is evidence that actors reap substantial benefits by residing in small-world structures (Uzzi and Spiro 2005; Schilling and Phelps 2007), understanding the dynamics 
of small worlds can offer valuable insight into the different opportunities and constraints these structures offer at various levels of their evolutionary progression. Depending on whether and to what extent the social system takes on the features of small-world architecture, the surrounding social context can have different and farreaching implications for the behavior and outcomes of social actors. This study therefore lays the foundation for exploring the role of the dynamics of small-world structures across multiple social systems, as well as over time within a single social system. More broadly, this inquiry responds to the growing calls for the investigations of the dynamics of social structure (Doreian and Stokman 1997). Second, by scrutinizing the intertwined relationship between the micro-level actions of social actors and the macro-level social structures of small worlds, we explore the mechanisms underlying the observed small-world evolutionary dynamics. We show that the actions of individual actors, guided by the evolution of the macro-level social structure, both contribute to the emergence a small-world system and plant the seeds of its decline. The micro-level actions not only can directly disrupt the small-world systems, but also can alter the social structure in a way that further constrains the continuity of small worlds, generating a self-reinforcing cycle of structure and action. This dual-level, micromacro analytical lens helps us unveil the origins of social structures, which derive from and subsequently shape the micro-level actions of individual actors (Baker and Faulkner 2009; Coleman 1990; Giddens 1984).

We conducted our investigation on a sample of organizations in the global computer industry by tracking network-related patterns resulting from their interorganizational ties over the period from 1991 to 2005. Interorganizational ties reflect a wide range of collaborative activities among organizations, ranging from joint product- and technology-development partnerships to marketing agreements. Our sample was particularly appropriate for exploring the question at hand for several reasons. First, such ties are ubiquitous and also critical for organizations in the computer industry. Second, this setting provided us with the rare opportunity to observe a dynamic social network over time, as such ties have been proliferating for a number of years. Third, most tie formations are announced publicly, providing a rich pool of historical data on the formation of interorganizational networks and their participants at multiple points in time. It is worth noting that the features of the global computer industry and the collaborative activity within it described above make this setting akin to several other high-technology sectors, including biotechnology and semiconductors, which have been analyzed extensively in recent years (e.g., Owen-Smith and Powell 2004; Powell et al. 2005; Rowley et al. 2000). 


\section{EVOLUTION OF SMALL WORLDS}

\section{The Micro- or Actor-Level Dynamics of Small Worlds}

Recent studies advanced a rigorous analytical formulation of the small-world effect using two key attributes: local clustering and global average path length (Watts and Strogatz 1998). The local clustering coefficient is measured as the number of actual links connecting all neighbors of a focal actor with one another, divided by the number of all possible ties among those nodes. The measure is subsequently averaged over all the actors in the network and shows whether one actor's direct contacts typically also know each other. The average path length, in turn, is defined as the average of all the shortest distances calculated as the lowest existing number of links between any two actors. This measure shows how far an actor is, on average, from everyone else in a social domain. Using these two dimensions, one can effectively distinguish small-world networks from both random networks, which have low clustering and low average path length, and regular networks, which have high clustering and high average path length. ${ }^{1}$ Interpolating between the qualities of the two, small worlds thus offer a unique combination of high local clustering and low global separation.

In our context, the dual macro-micro analytical approach requires considering small worlds' global properties of high clustering and low average path length in conjunction with the underlying micro-level dynamics of tie formation between actors. The role of micro dynamics in the formation of social structure can be observed clearly in a small-world system arising from interorganizational ties. At the foundation of such a system are the myriad actions of individual organizations. When pursuing such ties, organizations strive for valuable resources and aim to ensure survival within the constraints of the social structure (Baum et al. 2003; Powell et al. 2005). ${ }^{2}$ These individual actions by disparate actors eventually cumulate into macro social structures comprising complex interorganizational connections that enable the flow of information and other resources. The resultant

\footnotetext{
${ }_{1}^{1}$ A regular network represents a stylized structure where actors are ordered along a circle and each actor has $k$ neighbors. Setting $k$ to be an even number helps visualize the ring lattice as a network in which exactly $k / 2$ neighbors are located on the left and $k / 2$ neighbors on the right of the actor. In such a structure, each actor is thus connected to $k$ most proximate alters, resulting in a system with relatively high local clustering and a complete absence of shortcuts. Therefore, if an actor needs to cross to the "opposite side" of the circle to reach a more distant contact, it must go along the entire circle.

${ }^{2}$ It is important to note that understanding the micro-level actions of purposive social agents has a rich tradition in both sociology (e.g., Coleman 1990) and economics (e.g., Cowan et al. 2007; Jackson and Rogers 2007). This line of inquiry has also been extended to studies of interorganizational relationships (Baum et al. 2009; Ozcan and Eisenhardt 2009; Powell et al. 2005; Stuart 1998). Particularly as applied to social networks, exactly how much agency one can attribute to actors' independent volition versus their response to the pull from their surrounding social structure has been the subject of a considerable theoretical debate (e.g., Emirbyaer and Mische 1998; Sewell 1992). While resolving this debate is beyond the scope of this paper, our theoretical focus lies in emphasizing the role of the macro-level social structure as a key enabler or constraint of individual action (e.g., Giddens 1984; Zaheer and Soda 2009).
} 
social structure of interorganizational ties has been shown to be quite influential in shaping the tie formation by individual actors (Gulati and Gargiulo 1999; Powell et al. 1996). Two key actor-level processes are likely to explain the emergence of a small world in this context: (1) the formation of local ties that connect pairs of contacts located within the same network community and thus create dense clusters of tightly interconnected actors, and (2) the forging of bridging ties between actors from different clusters, which bind these clusters together into what becomes the small world (cf. Granovetter 1982).

Local interorganizational connections that culminate in tightly linked clusters emerge for a variety of reasons. First, since in most markets information regarding the availability, reliability, and resource profiles of potential partners is not perfectly distributed, many organizations tend to economize in their search for partners by selecting those with whom they have some familiarity, either directly or indirectly, through prior partners (e.g., Gulati and Gargiulo 1999; Shipilov and Li 2010; Zaheer et al. 2010). Local partnering enables organizations to effectively tap into a network that generates referrals to and background information on prospective partners. Second, densely connected clusters create reputational lock-ins, or situations in which noncooperative behavior may be costly because of the increased circulation of reputational information and the greater likelihood of collectively imposed social sanctions (e.g., Greif 1993). Finally, the formation of local ties can also occur as a result of technological similarity among organizations, in cases where organizations are aiming to scale up similar resource endowments or pursue incremental innovations (Wang and Zajac 2007).

The second key actor-level process in the generation of small worlds results from the propensity of at least some organizations to form bridging ties that run between clusters. Prior research has proposed that tightly connected clusters circulate mostly redundant resources and information, eventually becoming immune to the inflow of new information. In such contexts, bridging ties between clusters provide actors with efficient access to nonredundant information and novel resources that are typically unavailable through local ties (Burt 2005; Granovetter 1982). The bulk of the early research on the benefits of bridging ties concerned individuals, but a similar dynamic has recently been suggested for organizations entering into ties with other organizations (McEvily and Zaheer 1999; Ozcan and Eisenhardt 2009; Zaheer and Bell 2005). Formation of bridging ties can enable organizations to engage in a broader informational search, tapping the knowledge pools of diverse clusters through conversations among scientists, flows of personnel, and exchange of intellectual property that occur in 
interorganizational ties. The information, knowledge, and other resources that organizations acquire through such ties are likely to be nonredundant and valuable because they are derived from otherwise disconnected communities of actors. Incentives for organizations to pursue bridging ties are particularly robust in highly competitive and information-intensive settings, where the survival of actors rests on their ability to continuously access and recombine flows of diverse information, knowledge, and other resources (Eisenhardt and Tabrizi 1995; Lin 2001; Rowley et al. 2000). Within such settings, the existing macro-level social structure serves as a particular enabler of the formation of bridging ties when the distinct clusters of the social space serve as pockets of unique knowledge and creative insight, thereby allowing for the effective recombination of diverse inputs.

The formation of local and bridging ties is likely to shape the small-world architecture of the interorganizational system in two consequential ways. First, the formation of local ties with partners of current partners is likely to drive the emergence of dense and tight pockets of local connectivity, thus resulting in a highly clustered network. However, since interorganizational networks are typically sparse in that each organization has few ties relative to the number of firms in the industry (Davis et al., 2003; Powell et al., 2005), the network is unlikely to aggregate into one big cluster. It is, instead, likely to remain disaggregated as multiple smaller clusters. Second, the formation of bridging ties between these emergent clusters is likely to create shortcuts through the social space, thereby ensuring a high degree of global interconnectivity. In such a globally interconnected system, actors can reach one another through relatively short network paths. By virtue of the concomitant formation of many local and some bridging ties, we can thus expect to see the emergence of robust small-world that combines a high degree of actor's clustering with relatively short social distances between them.

\section{The Decline in the Formation of Bridging Ties and the Decline of the Small-World Architecture}

While these dynamics are likely to result in the formation of a robust small-world system, below we show how the changing macro-level social structure and the concomitant knowledge landscape of the industry evolved from being drivers of bridging tie formation to significant constraints upon it, planting the seeds of the decline of the system's smallworldliness. Since this social structure holds a plethora of entrepreneurial opportunities for knowledge recombination and the industrial landscape holds a strong incentive for such recombination, the formation of bridging ties can emerge and continue as one of the primary trends in collaboration. Under these structural conditions, the benefits that arise from bridging ties would be typically unavailable through other 
means in an emerging small world because local ties generate flows of largely redundant knowledge. Even if certain resource flows eventually reach every actor in the network, bridging ties can offer the benefits of speed and timeliness of access to this resource base. Thus, just as local search encourages organizations to form local ties, the advantages of access to diverse resources, knowledge, and information encourage at least some organizations to enter into bridging ties. As a result, although an early system may be composed of cohesive clusters of organizations that constantly grow in size and density owing to repeated formation of ties within them, with time the system also experiences an increased formation of ties spanning unoccupied network spaces between those clusters (Baum et al. 2003).

Note that the above account of organizations' pursuing bridging ties does not suggest that organizations astutely discern the structural gaps in a network structure and form bridging ties strictly on this basis. It is, rather, the quest for unique skill sets, information, and knowledge - hints of which organizations may discern in remote clusters through monitoring other firms' product development efforts, patent applications and grants, as well as interorganizational tie formation, among other activities - that drives the formation of bridging ties. As a small world takes form, actors within it are likely to reap benefits from the creative potential arising from the superior movement and recombination of information throughout the system (Schilling and Phelps, 2007). Consequently, we expect a locally clustered but globally tightly-knit small-world system to become the center of gravity in a larger network of organizations, and therefore to grow rapidly through the attachment of new clusters.

With the growing formation of bridging ties, we expect a new evolutionary dynamic to emerge. Bridging ties may eventually saturate the space between clusters, making clusters more and more interconnected. Working as pipes for the flows of information among clusters (Podolny 2001), existing bridges can thus gradually familiarize actors with the information and knowledge pool of other clusters and thus allow them to internalize some of that knowledge. As a result of this process, not only does the existing knowledge and resource base becomes more and more accessible to all network participants, but also, the new knowledge generated within clusters may become more homogeneous as it builds on increasingly similar antecedent knowledge bases. On a more general level, this logic resonates with recent studies suggesting that knowledge exchange is driven by and subsequently shapes the existing knowledge base in the industry (Baum et al. 2009; Cowan and Jonard 2009). More specifically, this dynamic parallels the findings of the computational work that showed that the decreasing 
path length in the network - by facilitating stronger knowledge exchange, sharing, and, as a result, the development of a common knowledge base - squeezes diversity out of the system (Lazer and Friedman 2007).

As a result, the increased information flows between clusters reduce the unique value of each cluster as a contributor of heterogeneous information. This reduction, in turn, diminishes the unique information qualities of the small world since the information, knowledge, and resources that are being circulated between clusters become more and more redundant. Structurally, the system undergoes a coalescence of clusters, thereby coming to resemble an agglomerated whole. As the network becomes less and less structurally differentiated (cf. Gulati and Gargiulo 1999; White 1981), the benefits of forming a new bridging tie to other clusters within the smallworld system diminish. More generally, at the same time that the informational benefits obtained through such ties decline, bridging will still entail the high risks and costs of forgoing the comfort and safety of partnering with current partners or partners of those partners.

The less structurally differentiated social system will thus begin to emerge as a substantial constraint on the formation of bridging ties. Under these conditions, the decline in the smallworldliness of the system occurs because as fewer new bridging ties enter the system and old bridging ties decay, it becomes more separated globally. It is essential to note that it is unlikely that the reversal in bridging tie formation will immediately restore the heterogeneity of clusters. The coalescence of clusters occurs over time, gradually reducing the heterogeneity of knowledge and resources across them. As this process unfolds, the clusters are also likely to develop an increasingly similar antecedent knowledge base. Following the decreased propensity of firms to form bridges and the reduction in the knowledge flow across clusters, it is therefore likely to take time for firms in clusters to restore their unique innovative base and revert to a truly heterogeneous state.

As a result of the emergent macro-level structural constraints on the formation of bridging ties, the resulting social structure is likely to retain high clustering, but it will be unable to preserve one of the key defining qualities of a strong small world: a low average path length. Using the networks of partnerships in biotechnology, Powell et al. (2005) hinted at a similar dynamic, whereby firms ended up connecting to other actors through multiple independent pathways, forged in pursuit of diversity. We take this idea a step further and suggest that the initial pursuit of bridging ties eventually eliminates the very diversity that these ties were meant to harness, thereby translating into a vicious recursive relationship between structure and action. 


\section{Self-Containment and the Fragmentation of Social Structure}

It is essential to remember that a small-world system represents the biggest connected component in a greater network. In other words, while it does represent the center of gravity in a network, the small-world system resides in a broader network space of isolated actors and smaller components. The dynamics of bridging tie formation previously described can work in concert with the structural dynamics related to the changing interactions between the small-world system and the greater outer network, as well as the changing prominence of the small-world system within it. These concomitant structural dynamics may create a strong self-reinforcing cycle that further destabilizes a small world.

Along with the decreasing diversity of information, an increasingly closed small-world network can develop a less diverse composition of actors and thus also beget strong shared norms of behavior and common mental models (Porac et al. 1995). Cognitive similarity, the self-reinforcing structural homogeneity of actors, and the possibility of sanctions against deviant behavior are all typical characteristics of increasingly closed systems. These characteristics, in turn, are likely to limit the accessibility of the small world to outside organizations, as the increasingly homogeneous organizations within the small world may accept fewer newcomers (Zaheer and Soda 2009). This dynamic mirrors some well-established findings documenting inertia and homophilous preferences in partnering (Li and Rowley 2002; McPherson et al. 2001). Additionally, the growing lack of diversity, possibly coupled with the decreasing innovation potential of the actors within the small world, can also make the network less attractive to newcomers, leading them to pursue collaborations beyond the small-world system. Taken together, the emerging constraints of the social structure can result in the decreased acceptance of outsiders and the decreased incentives for outsiders to join the small-world network and are likely to lead to what we refer to as the self-containment of small worlds. This trend manifests in the decreased formation of bridging ties between the occupants of the eroding small-world network and those of the outside network components, resulting in the small-world network becoming increasingly isolated from the greater outer network.

As the declining small-world network becomes more self-contained, the decreased innovative potential of organizations trapped within it can ultimately result in fragmentation. Since participation in disconnected and likely more diverse network components outside the core small world may carry more salient benefits for organizations compared with the prospects of staying in the eroding and increasingly homogenous small-world 
system, the formation of new bridging ties within the declining small world slows down. Thus, as older bridging ties decay, some clusters eventually disengage from the core system. The process of fragmentation, wherein a small world ceases to be the center of gravity for the larger network, is likely to further damage the innovative stock of the small world, additionally contributing to the decline of its complex structure.

In sum, we expect small worlds to be highly dynamic systems, whose evolutionary trajectories result from the reciprocal interaction between the evolving social structure of the industry and the micro-level organizational actions it elicits. An emergent small-world structure, where network clusters represent pockets of heterogeneous skill sets and knowledge, is likely to offer numerous entrepreneurial opportunities for knowledge recombination, thereby stimulating the formation of bridging ties. As the small-world structure matures, however, the excessive formation of new bridging ties gradually homogenizes the knowledge landscape across clusters, thereby eliminating the key benefits of diversity stemming from bridging ties. The subsequent decline in formation of bridging ties, which marks a major transition in the key behavioral dynamic that forged a small world in the beginning, contributes to the reduction of the smallworldliness of the system. Following the decline in the formation of new bridges and the decay of old bridges, the small-world system can be expected to lose its high connectivity wherein actors become separated by longer network paths.

Two parallel dynamics further reinforce this trend. First, as the small-world clusters become more interconnected, the system gradually transforms into a collection of "homophilous" actors who tap into an increasingly homogenized pool of information, knowledge, and resources, which drives their decreased innovative potential. This contributes to the growing self-containment of the system or its decreased attractiveness to and increased impenetrability by newcomers entering the system from outside. These circumstances therefore limit the ability of actors within the small world to form bridging ties to outside clusters. Second, the network undergoes gradual fragmentation, whereby entire clusters of organizations are likely to depart as the deteriorating small world loses the ability to serve as the center of gravity of an entire system of cooperating organizations. Taken together, these dynamics lead us to predict an inverted U-shaped evolution for small worlds, wherein the increase in the smallworldliness of the system is followed by its later decline.

We illustrate our prediction schematically in Figure 1. Graph A shows three initially disjoint network components. In graph B, these components become denser as a result of the formation of local ties. They also 
connect to one another through bridging ties, thus resulting in a mature small world. As the increased formation of bridging ties produces a homogeneous information space, it results in (i) a decreased formation of new bridging ties, leading to greater actor separation, and (ii) network fragmentation and self-containment, wherein one cluster disconnects from the small world while no new actors enter the system from outside (graph C).

\section{[Insert Figure 1 Here]}

\section{CORRESPONDING DEVELOPMENTS IN THE COMPUTER INDUSTRY}

It is important to note that the evolutionary dynamics of the firms' partnership network in 1996-2005 are reinforced by the evolution of the technological landscape of the computer industry. By the early 1990s, the vertically integrated industry of the old mainframes and minicomputers, in which several dominant players delivered complete end-to-end solutions, was largely replaced by a vertically disintegrated structure. This "new computer industry" (Grove 1996) consisted of a large variety of independent and technologically heterogeneous companies that focused on the design and production of a range of different but compatible computing technologies or components. The new industrial paradigm of the computer industry emerged alongside two distinct collaborative trends. On the one hand, many increasingly specialized firms began to collaborate within highly specific technological niches (e.g., microprocessors, storage devices, networking components, and system software), thus triggering the formation of local ties and the emergence of densely interconnected network neighborhoods. Rather than offering complete solutions, these firms sought to deliver products and applications within their own market niches. Echoing this trend, studies of the computer industry in the 1990s documented a rapid rise in collaboration among sellers of substitutes (Bresnahan 2000). As a result of these local collaborative linkages, the industry began to witness the emergence of pockets of production and innovation which quickly crystallized into distinct local clusters of the social system.

Notwithstanding the strong technological underpinnings of local ties, firms appeared to select into clusters in ways that transcended purely technical involvement. By creating strong relationships with other community members, firms could deploy exchanges that were characterized by high levels of trust and reciprocity, collective identify, and mutual support, inducing them to share their proprietary resources and knowhow (Garud et al. 2002). Given the risks of opportunism, strong cohesive relationships helped protect the community's technological viability by conveying key reputational insights about other firms and, if necessary, 
mobilizing collective action against those who failed to cooperate (Gomes-Casseres 1996). Thus, the formation of local ties, marked by a high degree of technological and social relatedness of the partners, facilitated the emergence of dense and cohesive clusters in the growing small-world network. ${ }^{3}$

The vertically disintegrated market structure of the 1990s also produced the need for extensive collaboration among the producers of complementary technologies, leading them to forge ties with partners located in other network clusters. Through these cooperative bridging ties, some companies in the computer industry assembled sets of complementary computer inputs - such as microprocessors, memory and storage, networking components, and software - into complete systems, or platforms, on which users would build and run applications (Malerba and Orsenigo 1996). Consider, for instance, the new client-server platform for computer networks, which incorporated a wide variety of complementary components, such as servers (e.g., Sun Microsystems), databases (e.g., Oracle), networking software (e.g., Novell), and a range of client-side applications (e.g., Netscape Navigator or Microsoft Internet Explorer). To guarantee their seamless interoperability, companies had to agree on certain shared standards for their products, such as the use of the same communication protocols (e.g., the TCP/IP protocol). This created the need for a particularly entangled bridging collaboration among firms residing in different technological layers. To underscore the importance of this trend, a representative of Microsoft noted: "In fact, the computer industry would cease to function if developers of complementary products that interact with one another in technically complex ways could not talk about how those products interact, now and in the future" (Bresnahan 2000: 19).

The formation of bridging ties could have been further facilitated by the fact that numerous platforms that had evolved by the mid-1990s (e.g., the dominant PC platform or Apple Macintosh) were designed as modular and open systems. These features made the individual subcomponents highly interchangeable and enabled them to be designed independently by specialized firms. These conditions, in turn, created a technological landscape that was, for the most part, conducive to the extensive formation of bridging relationships among the incumbents as well as to the attachment of entirely new clusters of entrants into the

\footnotetext{
3 Prior research has indicated the importance of social considerations in choosing and retaining partners (e.g., Gulati 1995; Larson 1992), which in turn suggests that the cluster structure of the computer industry is unlikely to have a one-to-one correspondence with the technological classification of firms. Rather, the structural boundaries of different communities - which ultimately shaped the development, accumulation, and sharing of knowledge in the industry - are best viewed as a complex product of the interaction of social
} 
industry. For example, while the period's most prominent computer maker - IBM - sourced its key parts from a few incumbent vendors, such as Intel (microprocessors) and Microsoft (operating system), the open architecture of the PC allowed users to substitute these standards for other IBM-compatible modules (Bresnahan and Greenstein 1999). In part, because of the continuously expanding technological features and capabilities of the PC platform, the core of the network increasingly attracted new market entrants and stimulated the expansion of the network. Taken together, these technological trends reinforced the formation of local and bridging ties, thereby contributing to the emergence of the locally clustered and yet globally interconnected small-world social structure of computer firms. This small-world structure further was a center of attraction for the outer network in the 1990s and absorbed a large population of new entrants.

Following 2000, however, the social mechanisms that led to the decline of the small-world system could also have been reinforced by several concomitant technological trends. First, the collaboration and transfer of knowledge among different clusters in the computer industry in the 1990s led to the emergence of relatively strong and self-contained technological platforms, such as the PC, as well as some centrally sponsored universal technologies for distributed computing, such as Java. Having grown out of cross-cluster collaboration, these mature technological blocks saw rapidly declining benefits of continued bridging collaboration. The arrival of Java, for instance, offered a particularly flexible and cheap standard for interoperability and system integration (Garud et al. 2002), thus decreasing the demand for proprietary solutions and cross-technology collaboration. Network clusters - many of which had earlier represented valuable pockets of complementary and innovative thought and had thus invited bridging relationships - now reflected mature competition, much of which was offering comparable solutions and pursuing a similar client base. To complicate matters further, most of the clusters were headed by a single leading firm or a group of leading companies which, in striving for overall market dominance, escalated cross-cluster competition and further reduced the opportunities for bridging collaboration (Bresnahan 1999). These competitive dynamics escalated as some companies, which were the undisputed leaders of their technological clusters (e.g., HP and Sun in the server cluster, Intel in the chip cluster, and Microsoft in the operating system cluster), began to expand control over multiple market segments, thus

and technological forces. Thus, analyzing the dynamics of specific patterns of interorganizational relationships can offer a particularly effective approach to tracing the evolution of the computer industry as a socio-economic system. 
triggering a departure from the distributed model of the late 1990s. As a result of these developments, the computer industry became more consolidated, less permeable, and less technologically diversified, thereby reducing the opportunities for bridging collaboration.

Second, the declining benefits of bridging ties were exacerbated by the rising costs and risks of such collaboration. The burst of the Internet stock bubble and the failure of many corporate "breakthrough" plans of the late 1990s resulted in a significant confusion in the computer industry, possibly leading many companies to revise their business models and collaboration strategies (Perkins and Perkins 2001). Many of the bridging partnerships of the late 1990 either failed to deliver on their promise or turned out to be dead ends (Datamonitor 2006). Under the changed environmental conditions, those who survived were driven to embrace the new reality by reducing now highly-uncertain cross-cluster collaboration and reverting to established strategies based on trust, long-term growth, and strong customer focus (Riolli-Staltzman and Luthans 2001). In line with these observations, some firms were beginning to increasingly support innovation either in-house or together with their users, rather than with complementary business partners through bridging relationships (Chesbrough 2003). Third, the pressures of competing substitutes and the need to reduce market uncertainty could have driven the firms in the computer industry into running self-sustained platforms and made it harder for the firms to form new cross-cluster bridging ties and to generate new integrative solutions, thereby stifling the creativity in the industry network. Key industry figures such as Michael Dell argued that many companies were in danger because "their business is fundamentally based on things that people aren't going to buy very much of anymore" and that those parts of the industry were driven "by reinventing what other people have already invented" (Pimentel 2003: B1). Not surprisingly, experts noted that the saturated computer market was stagnating: "The corporate market has become a replacement market ... there is no reason to buy anything now. They've bought everything they need" (Richtel 2000: C8). As another manifestation of this trend, studies of the computer industry at the time describe the noticeable industry-wide shift away from searching for and generating new creative solutions and toward a greater emphasis on cost reductions and operating efficiencies (Dedrick and Kraemer 2005). The homogenization of the technological and product space emerged alongside the increasingly more interconnected social structure, driving the diversity out of the production market. 
In parallel with the coalescence of network clusters and the increasing homogenization of the industry's knowledge base, the computer market in 2003-2005 saw an injection of entirely new technological fields and platforms beyond the core industry. These included, for example, pervasive computing which extended the computing paradigm to other domains and applications, such as portable devices or multimedia (e.g., Roussos 2005). While these emerging innovations opened up vast opportunities for new entrants, they also resulted in a significant fragmentation of the industry network by shifting the bulk of cooperative activity outside the core of the network. Given the network's stagnating core and its more innovating periphery, many new entrants as well as incumbents joined more peripheral network components in search of better opportunities. Thus, the homogenization of the knowledge base and the diminished benefits of cross-cluster bridging, coupled with the increased uncertainty of such collaboration, likely led to the decline of bridging activity in the system, an increase in the average path length, and the subsequent erosion of the small-world system. Further, the increasingly homogeneous and stagnating small-world core of the network could thus result both in its relative impermeability to outsiders and in its loss of attractiveness as the center of gravity for the larger network, leading to the network's self-containment and fragmentation. Taken together, these trends point to the co-evolutionary dynamics of the social structure and the technological landscape of the computer industry. More broadly, they are consistent with the earlier research that emphasized the critical interdependence between the dynamics of interorganizational networks and knowledge space in different industries (e.g., Rosenkopf and Tushman 1998).

\section{DATA, METHODS, AND ANALYSIS}

\section{Network Data}

We track an evolving network of interorganizational partnerships over 1990-2005. In this network, the nodes are organizations and the links are the undirected, unweighted partnership ties among those organizations. Networks of interorganizational partnerships are considered to offer a particularly rich and representative domain for the study of the embeddedness of economic action and have thus been examined extensively in prior studies (e.g., Gulati and Gargiulo 1999; Powell et al. 1996; Uzzi 1996). The computer industry, in particular, is one sector that has seen a proliferation of interorganizational linkages in recent decades. Since computer firms are constantly forging collaborative linkages not only with one another, but also with firms from other industries, we expected to observe a large connected network consisting of many different organizations and ties. Additionally, 
partnership networks are typically sparse because alliance formation is risky and costly. Global connectedness combined with a high degree of sparseness are important conditions in our case because it is only within such networks that the small-world property can be analytically pursued (Watts 1999).

In accordance with prior research, we used partnership data from Thomson Financial's SDC Platinum database (Casciaro 2003; Rosenkopf et al. 2001). In light of extant empirical work suggesting that the formation of interorganizational partnerships in the computer industry was less frequent in the 1980s than in the next decade (Gulati 1995; Hagedoorn et al. 2006), we left-censored our data at 1991.4 In order to achieve a degree of high precision in analyzing our network and produce a more fine-grained analysis of its temporal dynamics, we noted the exact month and year of each partnership announcement and traced the evolving network in half-year intervals. Finally, since a small number of alliances in our sample consisted of more than two firms, we incorporated them as sets of dyadic linkages (for a similar treatment, see Stuart 1998)

Since in the computer industry, only roughly 1 percent of all agreements reported by SDC have their precise dissolution dates on record, we followed prior research in modeling a five-year duration for a typical tie (Gulati and Gargiulo 1999; Lavie and Rosenkopf 2006; Stuart 2000). ${ }^{5}$ Beginning with partnerships initiated in 1991, we thus mapped ties into the partnership network conducting our analysis from 1996 onward, in half-year increments. This process produced a total of 20 periods for which we created 20 snapshots of the evolving social network. Given our focus on the global computer industry, we included only partnerships in which at least one partner was a member of the computer industry, as indicated by its primary four-digit SIC industry code

\footnotetext{
${ }^{4}$ For robustness, we also verified this condition empirically by collecting additional data on computer alliances between 1986 and 1990 . We used SDC as a primary source for this information, but cross-validated the data with another widely used repository of strategic alliances, the MERIT-CATI database. Our analysis indicates that in comparison to our focal period, the average annual count of newly formed partnerships over 1986-1990 was 15 times lower. The corresponding networks mapped for 1986-1990 were thus on average 14 times smaller than the systems over 1996-2005. Using this information, we then computed the percolation threshold of each network, or the probability of finding a large main component within it, defined as $1-N^{-1 / k}$. For the networks used in the study, our results showed an average percolation threshold of 0.92 , suggesting that a dominant main component in those systems was very likely. By contrast, the networks over 1986-1990 yielded a percolation threshold of 0.38, and so were two and a hald times less likely to be globally connected. We verified empirically whether this was the case in our data by computing the variation of component sizes as $\sum_{i}\left(n_{i} / N\right)^{2}$, where $i$ indicates the $i$-th component and $n_{i}$ is the size of the $i$-th component. Rather than capturing the total fraction of actors in the main component, this method allowed us to account for both the components' count and their size distribution. Results indicate that the study's networks over 1991-2005 were on average 7 times more connected than those over 1986-1990. Tracking MERIT-CATI partnership data all the way back to 1966, we similarly found that it was only in 1986 when the network acquired a main component greater than a single dyad, and the system did not develop discernable global topology until the 1990s. Taken together, these results indicate that the network's global architecture is beginning to take shape only in the 1990s and so our study's observation timeframe effectively captures the evolution of the social system since its early inception.

${ }^{5}$ For the 65 partnerships with precise termination dates in SDC reports, their average duration was also close to five years, which further supported our choice of the five-year moving window.
} 
(Computer and Office Equipment [SIC 3571-3579] and Electronic and Electrical Equipment [SIC 3612-3699]). Further, the main partnership activity had to fall within the computer industry according to its SIC code. These sampling criteria led us to recreate a highly dynamic network with 7,962 nodes between 1996 and 2005. The network grew from 374 companies in the first half of 1996 to a peak size of 6,221 actors at the beginning of 2004. Furthermore, not unlike other social networks, our network was also "disjoint" in each period as it consisted of multiple disconnected "components". Because a disjoint social network precludes uniquely defining and measuring small worlds, small-world studies tend to focus exclusively on features of the main component (e.g., Davis et al. 2003; Uzzi and Spiro 2005). We thus also focus on the main component, which includes all actors connected to one another by at least a single path of intermediaries.

\section{Macro-level Analyses of Small Worlds}

With the main component including on average $N=900$ actors and $k=3.5$ ties per actor, the network remained both large and sparse over 1996-2005, thus satisfying the basic requirement for small worlds that $N>>k$ (Watts and Strogatz 1998). According to extant research, identifying small worlds using the random network model entails, first, estimating the random network's parameters of clustering coefficient $\mathrm{C}$ and average path length $\mathrm{L}$ using the following theoretic approximations: $C_{R}=k / N$ and $L_{R}=\ln (N) / \ln (k) .{ }^{6}$ Using the ratios of real to random values, a small-world system will show $C / C_{R}>>1$ and $L / L_{R} \approx 1$ as a result of having a much higher clustering coefficient than the baseline random network but a roughly equal short average path length.

Averaged over 20 main components over 1996-2005, the mean $C / C_{R}=141.68$, which was significantly greater than 1, suggesting that observed clustering differed substantially from the random clustering. The mean $L / L_{R}=1.05$ suggested that the average path lengths for real and random networks were comparably short. Taken together, these results suggested that, on average, the network was both weakly separated and highly clustered, indicating a small-world structure. However, the standard deviations pointed to a relatively high variation in the clustering coefficient $(S D=102.42)$ and average path length $(S D=0.27)$ over time. This variation suggests that the small-world property of the evolving network might not be constant over time.

\footnotetext{
${ }^{6}$ The random network, which has found frequent use in prior analyses of small worlds (e.g., Baum et al. 2003; Davis et al. 2003; Kogut and Walker 2001) offers a particularly effective baseline model for two reasons. First, for any size and connectivity, it yields a low average path length $L_{R}$, thus coming very close to a prototypical small world in terms of actor separation. Second, it shows a weak clustering $C_{R}$, which makes it quite different from a small-world system in terms of cohesion.
} 
Over time, our network showed a roughly constant average degree $k$ but a highly variant size of the main component $N$. Since both of these parameters are used in evaluating the corresponding random clustering and average path length, changing $N$ or $k$ is likely to affect these baseline properties. For example, if the average degree remains constant but network size increases, then, given their analytic approximations, the random average path length will increase while random clustering will decrease. In effect, we are likely to obtain a disproportionately high ratio of real to random clustering and a disproportionately low ratio of real to random average path length. Such an outcome is less of a problem in cross-sectional analyses where the observed network does not change over time. However, in dynamic analyses, where the network's size changes, not accounting for these changes can lead to inaccurate estimates of the small-world property. To fully eliminate the distorting effect of changing network size, we therefore used size-adjusted ratios of clustering coefficients $\alpha\left(C / C_{R}\right)$ where $\alpha=1 / N$, and average path lengths $\beta\left(L / L_{R}\right)$ where $\beta=\ln (N)$. Using the adjusted measures, we subsequently explored the evolutionary pattern of the small-world structure. ${ }^{7}$ Figure 2 a reports the values of the comparative size-adjusted ratios of clustering and average path length, which are additionally rescaled between 0 and 1 (by dividing each value by its maximum over the entire period). The Figure $2 \mathrm{~b}$ reports a combined summary statistic of the small-world quotient $Q=\alpha\left(C / C_{R}\right) / \beta\left(L / L_{R}\right){ }^{8}$

These trends support our prediction of the inverted U-shaped evolution of the small-world network, suggesting that while the network shows some features of a small-world system, it does not remain equally "small-worldly" all the time. Specifically, Figure 2a demonstrates an initially decreasing trend in average path length and an increasing trend in clustering. This pattern is consistent with our prediction of two parallel firm behaviors: the formation of bridging ties, which reduces the average path length, and local search fostering the formation of local ties, which increases clustering. The growing clustering and the decreasing average path length jointly account for the early rise of the small-world structure, which maps onto 1996-2000. Then, around 2000, the average path length begins to rise while the average clustering coefficient starts to decline. Taken together,

\footnotetext{
7 To bolster our reasoning analytically, we conducted a series of computational experiments using first standard and then adjusted smallworld metrics. Our simulations indicated that while the unadjusted measures indeed introduced a substantial scaling error into the smallworld parameters, performing the suggested corrections was very effective in eliminating these undesired effects and helping obtain more robust measurements. These results are unreported but are available upon request.

${ }^{8}$ Note that we also rescaled the quotient by $\alpha / \beta$ to control for the periodic effects of network size. It is important to note that this change echoes earlier research that noted that $Q$ varies strongly with network size (Baum et al. 2003). For example, in our review of the
} 
these dynamics mark the beginning of the decline of the smallworldliness of the system, mapped onto 20002005. Our findings on the combined quotient $\mathcal{Q}$ in Figure $2 \mathrm{~b}$ provide consistent evidence. ${ }^{9}$

[Insert Figures 2a and 2b Here]

\section{Robustness tests}

In a series of tests, we verified the robustness of the results, previously reported in this paper, using alternative methods of constructing and tracing the dynamic interorganizational network. First, we re-ran the entire analytic procedure on networks with duration of ties set to 3, 4, 6, and 7 years. Second, rather than tracing the network's evolution in half-year increments, we applied three-month and one-year resolutions, respectively. Both of these analyses yielded highly consistent results in terms of the produced evolutionary trend of the small-world system, indicating a robust curvilinear pattern with the inflection in 2000. Finally, to investigate whether the dynamics of the small world could be sensitive to incomplete partnership data in some periods (Lavie and Rosenkopf 2006; Schilling 2009), we performed multiple simulation tests by randomly removing up to $50 \%$ of ties from each network, and recalculating the small-world parameters. Even after such significant data compromises, the overall U-shaped evolutionary pattern of small worlds remained unchanged. These results echo the findings of prior studies, which demonstrated that the global dimensions of social networks are quite resilient to data incompleteness (e.g., Kossinets 2006).

In the next series of tests, we extended the analysis of small worlds beyond the structure of the main component to the level of the global network. Since the traditional metric of average path length is undefined for disconnected networks, we used average inverted path length as $2 /[N(N-1)] \sum_{i<j} 1 / D_{i, j}$, where $1 / D_{i, j}$ is the inverse of the shortest distance between $i$ and $j$. It is set to " 0 " if $i$ and $j$ are entirely disconnected and " 1 " if $i$ and $j$ have a direct tie, thus convening the notion of proximity, rather than distance. We obtained the baseline parameters of the random networks using Monte-Carlo simulations and then estimated the size-adjusted $C / C_{R}$

\footnotetext{
recent organizational literature, we found that the value of $Q$ associated with small worlds varies rather strongly, from as low as $Q=2$ in smaller networks (e.g., Uzzi and Spiro 2005) to as high as $Q=60$ in larger networks (e.g., Davis et al. 2003).

9 The trends revealed past the inflection point in the small-world are partly consistent with our theoretic predictions. While we expected the average path length to increase as a consequence of the predicted decline in bridging tie formation, we also predicted that the clustering coefficient would remain constant. However, in addition to rapidly growing actor separation, we also witness a decreasing trend in clustering. Therefore, as we analyze the micro-trends underlying the growing average path length in the next section, we also complement these analyses by investigating the possible drivers of the decreasing degree of clustering.
} 
and $L / L_{R}$. Our analysis reproduced a qualitatively similar inverted U-trend in the global network's smallworldliness showing a robust inflection point around 2000.

\section{Micro-level Analyses of Actor Behaviors}

While the above analysis highlights the dynamic nature of this global small world, it leaves a range of unanswered questions about the potential micro-level drivers of these dynamics. Following our theoretical argument, we therefore decomposed the small-world system in each observation period into sets of local ties within cohesive clusters of firms and bridging ties between clusters. We then explored the relationship between the changing tie configurations at the firm level and the macro-level dynamics of the global small world. ${ }^{10}$

To distinguish bridging from local ties, we analyzed the cluster structure of the evolving network in each period. Detecting clusters has recently been the focus of research in sociology (Davis 1967; Johnson 1967) and physics (e.g., Guimerà and Amaral 2005; Newman 2004). The central idea is to partition the network into cohesive and dense groups of actors in such a way that the density of ties within groups is higher than between them. To generate this result, earlier work typically relied on a standard method known as hierarchical clustering (Wasserman and Faust 1994). While this method is useful for certain types of networks, particularly those in which the cluster structure can be inferred from actors' attributes (such as co-affiliation in joint social groups), it is less appropriate in our context. This is because hierarchical clustering requires making a range of assumptions with respect to the number of clusters in the network or their sizes. These assumptions become increasingly tentative for larger networks that potentially form as a result of complex actor behaviors.

Given that we had no prior knowledge about the segmentation of our network into clusters based on firms' attributes, we used a clustering technique that takes into account the betweenness centrality scores of network ties (Girvan and Newman 2002). This technique is particularly effective in partitioning a strongly clustered small-world network, in which ties with higher centrality scores are likely to indicate the natural dividing

\footnotetext{
10 Our focus on cross-cluster bridging captures a stronger form of bridging than the more encompassing concept of brokerage defined as spanning any two otherwise unconnected contacts (Burt 1992). In the latter form, the contacts may belong to the same cluster and thus offer each other little informational value. Put differently, they offer a lower incentive for establishing a bridging connection than firms that come from a different cluster, linking to which provides an entrée into an entirely new community of firms with potentially rich and novel knowledge and resource pools. We therefore expected between-cluster bridging ties, rather than simply ties to disconnected contacts, to play a very significant role in accessing diverse knowledge and resources. To ensure that we are not sidestepping an important empirical factor in small-world dynamics, throughout the paper we also discuss results based on a within-cluster metric of brokerage, such as network constraint (Burt 1992).
} 
lines between clusters. For our network, it thus offers a more effective approach to identify cohesive clusters than the standard hierarchical clustering (Girvan and Newman, 2002).

To determine the optimal division of our network into clusters in each year, we used the modularity index. This index offers an effective way to evaluate the quality of a given division relative to other divisions (Newman, 2003). Formally, modularity is defined as $M=\sum_{i}\left(l_{i} / E\right)-\sum_{i}\left(e_{i} / E\right)^{2}$, where $l_{i}$ is the number of local ties within the $i$-th cluster, $e_{i}$ is the number of all ties (local and bridging) connecting to actors in the $i$-th cluster, and $E$ is the total number of network ties. Modularity compares the strength of the cluster structure that was produced by a given division (as indicated by the summed fraction of local ties) to a cluster structure in a fully random network of the same size and degree distribution. The random network is unlikely to have any community structure, thus constituting a robust null model. If the division results in a weak cluster structure, then modularity is close to 0 . By contrast, if the division produces a strong cluster structure, then modularity is higher and should exceed 0.3 (Newman and Girvan 2004). Identifying the network's cluster structure thus involves maximizing the value of modularity over all possible divisions, and making sure that that maximum score is greater than 0.3. In partitioning our network, we obtained an average modularity score of 0.72 , which indicated a consistently robust partitioning across all years. This partitioning produced between 6 clusters in 1996 and 65 in 2004. The size of a typical cluster in our network ranged on average from 7 firms in 1996 to 34 firms in 2005.11

\section{Formation of Bridging Ties}

Having identified the network's cluster structure, we designated each network tie as local (i.e. both partners belong to the same cluster) or bridging (i.e. the partners belong to different clusters). The respective counts ranged from 124 local ties and 10 bridging ties in 1996 to 2,429 local ties and 391 bridging ties in 2004. On average, the proportion of bridges in the main component was $15 \%$. Yet, this ratio was not constant, but showed a major transition in firms' pattern of forming bridging ties around 2000, when the pattern of increasing bridging tie formation shifted to a pattern of decreased bridging (See Figure 3). To account for the potential impact of

\footnotetext{
${ }^{11}$ Because these results rely to some degree on the chosen partitioning procedure, we verified them against alternative methods. In particular, we used the method proposed by Guimera et al. (2004) which is based on an optimization technique called "simulated annealing". The obtained divisions corresponded closely to the ones identified using the betweenness centrality approach.
} 
changing network size on the formation of bridging ties, we normalized their raw count by the size of the main component in each period. This gave the average number of new bridging ties per firm in each period and included both new bridging ties between firms that were already part of the small-world network at time $t-1$ and new bridging ties between incumbent firms and newcomers who joined the system at time $t$.

\section{[Insert Figure 3 Here]}

Relative to network size, there is an increased supply of new bridging ties during the entire phase of rising smallworldliness. This observation supports our prediction of the initial small-world growth due to continued accrual of new network clusters and the decreasing separation of clusters that were already part of the smallworld main component. However, as time goes by, the continued supply of new bridging ties has profound implications for the degree of small worlds. As organizations saturate the empty network space between clusters and make themselves increasingly more interconnected, the social structure begins to act as a key constraint on the formation of new bridging ties in that the densely interconnected clusters cease to be pools of unique knowledge and resources. Instead, they are likely to offer increasingly homogeneous information, thus reducing the benefits of new bridging contacts. Prior to 2000, dense clusters were interconnected by multiple bridging ties, effectively yielding a small-world system that was characterized by a low average path length. However, as the formation of new bridging ties declined after 2000 and the existing bridges dissolved, firms became separated by longer pathways, which in turn lead to the increase in average path length and the diminishing small-world property.

Our macro-level analysis also suggested a steadily diminishing clustering coefficient following 2000. This process could be related to the concomitant local tie dynamics within clusters and, in our case, to firms' changing propensities to form new local linkages. Thus, even though we did not explicitly focus on this mechanism in our theoretical discussion, we conducted an additional exploratory analysis of local tie formation within clusters in order to understand the possible firm-level determinants of the declining clustering. Figure 4 traces the counts of all newly formed local ties within the main component normalized by its size: we observe high rates of local tie formations until 2000, followed by a sharp decline. The initial rise in local ties thus supports our argument of increasingly dense clusters prior to 2000, while their drop provides a key micro-level explanation for why, at the 
level of the main component, we see a declining clustering coefficient over 2000-2005. Altogether, the results provide a complementary explanation of the declining smallworldliness past 2000.

[Insert Figure 4 Here]

\section{Robustness tests}

We conducted additional analyses to rule out some alternative explanations of the observed firm-level dynamics of bridging and local tie formations. A key alternative explanation refers to the changing opportunity set for the formation of these distinct types of ties, thus suggesting that the observed dynamics of small worlds could be driven predominantly by chance. Specifically, one could expect a network consisting of more clusters to promote the formation of bridging rather than local ties by changing the likelihood of chance encounters among actors (Blau 1977). By contrast, clusters of growing size could facilitate the formation of cohesive local ties at the expense of non-redundant bridges. To explore this possibility, we tracked for each firm the proportion of available contacts in other clusters to those available in the firm's own cluster. The aggregated trend showed a consistent increase throughout the observation period, thus ruling out the possibility that random perturbations in the network structure could trigger the observed dynamics of the small-world property.

Further, to ensure that the key small-world destabilizing trend of growing average path length could indeed be attributed to the patterns of bridging tie formations between clusters, rather than within them, we explored the levels of bridging tie formation inside clusters. To do so, we used average firm constraint:

$C=\left[p_{i, j}+\sum_{k}\left(p_{i, k} p_{k, j}\right)\right]^{2}$, where $p_{i, j}$ is the proportion of firm $\imath$ s time and energy invested in the tie with firm $j$

(Burt 1992). ${ }^{12}$ High within-cluster constraint captures the lack of structural holes in the firm's local network neighborhood, while low constraint signals a position rich in bridging ties. The levels of constraint showed a remarkable degree of stability over time (with a mean $C=0.75$ and a low standard deviation around 0.03 ). This additional analysis confirmed that both the observed increase in the small-world property prior to 2000 and its later decline could not be triggered by bridging tie formation within clusters.

Yet another alternative explanation is that an exogenous shock in the computer industry around 2000 could trigger a structure-loosening event in the network, which could explain some of the changes in the 
observed tie formation dynamics around that period. A structure-loosening event is believed to occur when "rich get poorer" or when highly central actors forgo a central position while more peripheral actors become more central. Replicating the original approach of Madhavan et al. (1998) who documented such an event in the context of the global steel industry, we conducted formal tests for the presence of a structure-loosening event in our network in 2000 by estimating the correlations of actor-level degree centrality across the pre- and post-event windows. Specifically, we chose two non-overlapping five-year windows to the left of the event year (1995-1999) and to the right (2000-2004), including the event year in the post-event window to fully account for the consequences of the exogenous shock in 2000 (Madhavan et al. 1998: 449-450). Our results indicated a high preand post-event degree centrality correlation at the firm level of $0.8431(p<0.01)$ which was significantly above the reported correlation of 0.38 in Madhavan et al.'s (1998) paper. Using consistent five-year windows, we also compared this correlation with correlations estimated for three alternative event years 1998, 1999, and 2001, respectively. None of these additional analyses produced significantly different correlations between pre- and post-event windows, thus rejecting the structure-loosening hypothesis for our network.

Finally, networks could emerge due to actors' preferential attachment in forming network ties, rather than due to the formation of local and bridging ties. Such preferential patterns typically result in highly skewed distributions of actors' degrees that are consistent with a power-law distribution (Barabási and Albert 1999). To examine the possibility of preferential attachment in our data, we first analyzed actors' degrees across our 20 observation periods. None of the 20 networks indicated a robust power-law distribution following a straight line on the log-log chart. Second, using the formalized approach, we rejected the power-law hypothesis in 16 of the 20 cases. For the four cases where the power-law hypothesis could not be rejected, this could be a result of insufficient data as the network was still relatively small at that time (Clauset et al. 2009). In addition to conducting the test for the presence of the power-law distribution, we also verified the preferential attachment hypothesis by estimating the correlation of degrees for pairs of connected actors. A strong and negative pairwise correlation could be a sign of preferential attachment because it would suggest that actors with low degrees generally tend to pursue ties with more central actors (Newman 2002). Our results indicated that the degree

12 For an undirected and unweighted network, such as ours, $p_{i, j}$ simplifies to $d_{i, j} / d_{i}$, where $d_{i}$ is $i$ s degree and $d_{i, j}$ is $i$ s degree with $j$. 
correlation for any two connected actors was only 0.01 inside the main component, and 0.19 overall (both significant at $p<0.001$ ), thus providing no support for preferential attachment. In sum, for the vast majority of our longitudinal data spanning the formation, inflexion, and decline of the small-world system, these tests showed that preferential attachment is unlikely to affect the evolutionary dynamics of the network.

\section{Self-Containment and Fragmentation of Small Worlds}

We hypothesized that the growing homogenization of the information space in a declining small-world system may lead to declining diversity of firms in the main component. Lower diversity, in turn, may lead to selfcontainment, whereby the deteriorating small world becomes impenetrable for firms from outside the main component, and fragmentation where the small world loses some of its clusters altogether. We examined the degree of diversity of firms in the small-world system using Shannon's (1948) measure of information entropy. We calculated this index individually over two distinct sets of firm attributes: (i) the first two digits of the SIC codes from Compustat which correspond to broader industry areas in which firms operate, and (ii) and the twodigit technological subcategories of firms' patent applications, extracted from the NBER patent database (Hall et al. 2001). ${ }^{13}$ The resulting diversity trends - computed for the entire population of firms in the small-world network and plotted in Figures $5 \mathrm{a}$ and $5 \mathrm{~b}$ - support our prediction of the increasing homogenization of the system after $2000 . .^{14}$

\section{[Insert Figures 5a and $5 \mathrm{~b}$ Here]}

These trends reaffirm our prediction that the homogenization of the information space gradually reduces the diversity of firms that populate the small-world network. Progressive homogenization of the main component and decreasing diversity of the information flows within it may contribute to the diminished appeal of the core system to newcomers. This, in turn, is likely to diminish the incentives for newcomers to join the small world, while the increasingly homogeneous population of firms within it may also make entry more challenging for firms seeking greater diversity. By contrast, companies that stay in the rapidly enclosing network are more likely

13 To calculate the degree of firms' technological diversity, we examined the different knowledge areas in which firms apply for patents in a given year. We extracted the yearly counts of patent applications received by the US Patent and Trademark Office from the NBER database. Given that systematic patent data is available until 2002, we focused on the period 1996-2002 and differentiated between the technological areas of patents using the 36 patent subcategories indentified by Jaffe and Trajtenberg (2002).

14 We also replicated these results using Blau's (1964) index of diversity. Further, we established that not only does the aggregate system become more homogeneous in the decline phase of small world, but also that the individual clusters within the system follow the same 
to be driven by inertia and homophilous attachment, further driving down the network's innovation potential. Taken together, these processes are likely to lead to the increased self-containment of the small world and its growing isolation from the broader network. Our results confirm this dynamic. The newly formed bridging ties by actors within the small world to clusters outside of the small world declined following 2000, indicating the network's growing self-containment.

The decreased attractiveness of a small-world system can also make it more difficult for organizations to develop and sustain current bridging ties. This can result in the fragmentation of the system, wherein entire clusters of firms begin to leave the core small world and become stand-alone entities outside of it. The heightened formation of new interorganizational partnerships predominantly outside the small-world system reinforces this process. These new partnerships are driven by both newcomers to the network and organizations leaving the small world. As a result, the center of gravity in network formation shifts away from the small-world component to the disconnected network peripheries. Based on our data, Figures 6a and 6b support these trends. In contrast to the preceding period, declining smallworldliness of the core main component is accompanied both a sharp increase in the total number of components in the system and an increased formation of new ties outside the main component.

[Insert Figures 6a and 6b Here]

\section{Statistical Modeling of Attachment}

We also statistically modeled the dynamics of attachment. Our goal was to validate the previous descriptive analyses on role of the formation of local and bridging ties in determining the rise and decline of the smallworldliness of the system. We used counts of newly formed ties for each organization in each time period as our dependent variables, differentiating between bridging and local ties in the main component. Using a binary variable, post-inflection, we distinguished the pre- and post-inflection period in small-world evolution (0 before and 1 after 2000). Since we predict the formation of bridging ties to decline post 2000 , we expect the post-inflexion binary to have a negative effect on the formation of bridging ties.

pattern of growing homogenization. To capture this trend, we calculated within-cluster diversity indices of firms using both Shannon and Blau' approaches, and subsequently averaged the results obtained for clusters over the entire small-world network. 
Because our tests established overdispersion in the count-dependent variables (annual counts of bridging and local ties) - a common feature of many count variables (Hilbe 2007) - we used a set of negative binomial regression models. Negative binomial regression may be considered a generalization of the standard Poisson model particularly suited to dealing with overdispersion because it incorporates an additional parameter, which introduces an unobserved heterogeneity effect into the conditional mean. The negative binomial specification is estimated using the maximum likelihood method and allows for greater variance than the Poisson model, thereby avoiding Poisson's downward bias in estimation of standard errors in situations of overdispersion. ${ }^{15}$

In the second set of models, we aimed to verify whether micro-level actions indeed translate into macrolevel outcomes according to the predicted patterns. Specifically, we sought to understand if bridging and local ties significantly influence the average path length and clustering of the system, respectively. Since system-level path length and clustering are simple averages of firm-level values, we used OLS regressions to model the firmlevel average path length and clustering as a function of a firm's bridging and local ties. Our goal here was to ensure that the relationships between bridging ties and path length and local ties and clustering are statistically meaningful, and that these relationships hold throughout the evolutionary trajectory of the small-world system. ${ }^{16}$

To ensure the robustness of our results, we controlled for each firm’s profit margin, debt ratio, logged headcount (all lagged by one year), and degree centrality, measured as the logged number of partnership ties that the firm had formed in periods $t-1$ to $t-5$. To account for any unobserved heterogeneity in alliance formation among organizations, we also tracked the firm's prior partnership frequency using the logged number of all past ties created by the firm between 1991 and $t-5$. We further used dummy variables to control for the primary business group affiliations (captured by 2-digit SIC codes) and to denote whether the firm was located inside the main component at $t-1$. Finally, to control for network dynamics at the level of the entire system and their possible impact on firms' predicted average path length and clustering, we used the aggregate count of all new ties formed at $t-1$ outside of the main component.

\footnotetext{
${ }^{15}$ Following the Hausman test, which indicated that conditional fixed-effects and random-effects models were comparable, we also estimated all our models using the random-effects variants of the negative binomial regression. Results were consistent with those we estimated using negative binomial with robust standard errors.

${ }^{16}$ Since values of actor-level clustering are bounded between 0 and 1, we re-ran Models 4, 6, and 8 using Tobit estimation. The results remained unchanged.
} 
We estimated robust standard errors adjusted for hetersokedastic variance of the error term (White 1980). To adjust for non-independence of observations, which is a common problem in network data, we used a two-pronged approach. First, we adjusted for non-independence of observations by clustering standard errors at the firm-level, which minimizes the risk of downward estimation of standard errors. Second, consistent with prior research (e.g., Baum et al. 2005; Marsden and Friedkin 1993), we modeled network autocorrelation as a form of influence process: $y_{t+1}=\varrho W_{j, t, t j, t}+x \beta+\varepsilon$, where $W_{i j, t}$ is the industrial similarity between the focal actor and all other actors $j$ in the network at time $t$, and $y_{j, t}$ is the corresponding lagged dependent action of $j$ (e.g., total count of new bridging ties created by $j$ at $t$. We have specified $W_{i j}=1$ if $i$ and $j$ belong to the same business group according to the first two SIC digits, and 0 if otherwise. Based on our analysis of the empirical context of computer industry, the 2-digit SIC groupings are a salient differentiator in the industry and is therefore an appropriate similarity metric to capture network influence processes. ${ }^{17}$

Table 1 presents correlations among our variables. Throughout the estimation process, we exercised extreme care in dealing with possible concerns of multicollinearity. Condition indices were sufficiently low to ensure both the power of the analyses and the stability of the estimates were adequate in all our models (Belsey et al. 1980). It is important to note that network autocorrelation effects in all models (Table 2. Model 1-8) were positive and statistically significant. This suggests the possible presence of network influence processes, which were purged out of the estimated predictors. Consistent with our exploratory actor-level analysis of network data, the negative effect of the post-inflexion binary variable in Model 1 suggests that the formation of bridging ties declines significantly following the first half of 2000, where we observe the inflection point in the adjusted smallworld quotient. These results are consistent with our descriptive finding of the first rising and then declining trend in the formation of bridging ties. We also see a similar trend in the formation of local ties (Model 2), although the drop-off in this trend after the inflection point is less severe than the drop-off in bridging ties. In additional tests, we have confirmed these trends by using half-year time fixed effects. ${ }^{18}$

\footnotetext{
${ }^{17}$ In a set of robustness tests, we additionally modeled network influence based on three alternative measures of similarity: (1) size similarity, based on headcount; (2) financial performance similarity, based on return on assets; and (3) technological similarity, based on the distribution of firms' alters across the 2-digit SIC industrial space. In all these instances, the effect of the similarity measure on the dependent variable was weaker compared to the one based on industrial similarity and reported here; all other effects remain similar. 18 The time binary variables used in our models may capture the impact of some market shock on the evolution of small worlds, rather than the role of structural dynamics. To investigate this possibility, we created an additional measure that reflected the aggregate sales of all firms in our sample for the given year. When used instead of the time effects models (we could not use sales and year effects jointly as
} 
Models 3 and 4 confirm our previously descriptive result that average path length increases post the inflexion point while clustering goes down. These results suggest that the observed inversion in the small-word property is statistically meaningful. Models $5-8$, in turn, render support for the theoretical link between the micro-level mechanisms of the formation of bridging and local ties and the macro-level parameters of path length and clustering, respectively. Specifically, newly formed bridging ties - by virtue of introducing critical shortcuts in the system - have a strong negative impact on the average path length (Model 5).${ }^{19}$ Local ties also register a negative effect on path length (Model 5): an addition of any tie can potentially add to the connectivity of the system, although the effect of local ties is noticeably weaker than that of bridging ties. Consistent with our prediction, local ties provide a significant positive contribution to clustering (Model 6). Results in Model 7 further suggest that in the post-inflexion phase, the negative impact of new bridging ties on path length is attenuated. This is aligned with our observations that as the system gets more globally interconnected and the space between clusters is saturated, the marginal contribution of each new bridging tie to path length is diminished. ${ }^{20}$

\section{DISCUSSION}

In this study, we have explored the evolutionary dynamics of one small-world network. Our central contribution has been to highlight that at least some small worlds can be seen as highly dynamic systems that follow an inverted U-shaped evolutionary pattern, wherein the increase in the smallworldliness of the system is followed by its decline. We have decomposed small worlds to the actor level of analysis, explaining the difference between local ties that agglomerate into tightly linked clusters and bridging ties that connect those clusters. Early in the formation phase of small worlds, the social structure offers numerous entrepreneurial opportunities for the recombination of diverse knowledge and resources across different and sparsely linked clusters, thereby

they represent comparable year-level fixed effects), the aggregate sales models produced a significantly worse fit to the data while leaving all other established effects intact. Coupled with our controls for firms' financial and resource endowments, this result suggested that exogenous market or competitive dynamics could not be held solely accountable for the observed changes in the social structure. ${ }_{19}$ Baron and Kenny's (1986) more stringent test for the significance of mediation indicated that the partial mediating effect of bridging ties is statistically significant at $p<0.001$. This result supports the prediction that the dynamic of bridging tie formation represents a statistically significant explanatory trend behind the observed temporal variation in the average path length of the system. ${ }^{20}$ In a set of additional analyses, we used the constraint measure (Burt 1992) to model within-cluster bridging tie formation. We did so to ensure statistical concordance with our prior visual analyses and the accuracy of our inferences with respect to the insignificant role of within-cluster bridging in the dynamics of small worlds. Results showed random variation of constraint over time that was indistinguishable from zero. This result confirms that within-cluster bridging plays no discernable role in the dynamics of small worlds. 
stimulating the formation of bridging ties. Increased formation of bridging ties, in turn - by making clusters more interconnected and as a result more homogeneous in the information, knowledge, and resources they offer - eliminates the key driver behind it: the diversity of the resource pool. Thus, the evolving social structure turns from enabling the formation of bridging ties to becoming a source of constraint with respect to it. As fewer and fewer firms pursue the diminishing benefits of bridging ties, the small world loses its unique feature of low global separation, reflecting a decline in the system's smallwordliness. In this way, the very process of social actors' entering into bridging ties - the dynamic that is key to the formation of a small world structure - works in recursion with the evolving social structure to catalyze the subsequent decline in smallworldliness of the system. This trend is coupled with (1) increasing homogenization of the system and its self-containment, wherein fewer actors are able to enter the decreasingly diverse system from the outside; and (2) fragmentation, which manifests in the separation of some clusters from the system as the declining small world loses its appeal. Taken together, these trends account for the inverted U-shaped evolutionary path of the small-world system.

Our central finding requires one important caveat. We relied on a single network in this analysis, so the study's generalizeability is certainly a question for future research. It is possible that our findings are peculiar to the computer industry only. It is also possible that the theoretical mechanisms explicated here could apply to a range of other interorganizational or interpersonal settings where individual action is closely intertwined with the set of opportunities and constraints produced by the evolving macro social structure. Other similar contexts worthy of scrutiny could thus include networks of interlocking directorates (Davis and Greve 1997), venture capital (e.g., Sorenson and Stuart 2001), and investment syndicate (e.g., Shipilov and Li 2008) ties among organizations, as well as networks of communication among individuals (e.g., Brass 1984; Burt 2004). We would also expect less knowledge-intensive settings, in which actors' survival depends less on gaining access to cuttingedge skillsets and knowledge through network ties, to display less dynamic network structures (cf. Lin 2001).

One could also consider two alternative explanations of the observed dynamics of the small-world system. One possibility is that the increasing pursuit of bridging ties would saturate the network space to the extent of ultimately producing a single cohesive cluster. As a possible consequence of this process, network members would then start seeking connections to clusters located outside of what once used to be the core small world. This alternative explanation, however, has several shortcomings on conceptual grounds. First, this 
argument rests on the assumption that actors within a small-world system continue to form bridges at an increasing rate even though the actual advantages of bridging at some point diminishes due to the growing interconnectivity of clusters. Second, actors located outside of the small-world network would have to show an undaunted interest in joining the small world despite the eroding value of informational space. Finally, for this argument to hold, actors would have to withstand the strong lock-in pressures that characterize an increasingly homogeneous small world, and continue nevertheless to actively seek bridging opportunities outside of it.

These concerns make it a rather unlikely scenario and, not surprisingly, our empirical results invalidate this alternative explanation. First, the formation of bridging ties in the network follows a clear curvilinear pattern. This confirms that firms indeed display a lower propensity to form new bridging relationships once the small world has become more interconnected. Second, in the post-inflexion period, the small world suffers from increasing self-containment, so that new clusters become less likely to join the system from the outer network. Finally, because the post-inflexion small-world system also appears to be increasingly more homogeneous, it contributes even more to growing self-containment by (i) limiting the acceptance of outsiders by actors inside the small world, and (ii) discouraging actors inside the small worlds from pursuing external partnerships.

Another possibility would be to attribute the declining formation of bridging ties to the shifts in the opportunity space within the social structure. Specifically, one might argue that as the formation of bridging ties escalates and the space between clusters becomes more saturated, the available structural opportunities for forming new bridging ties disappear. By this logic, even though many firms would still remain keen on entering into new bridging ties, the global system would make it increasingly difficult for them to become brokers due to its changing inner topology. While this argument is simple and intuitively appealing, for it to hold, the network would have to reach extreme levels of saturation between clusters. Indeed, most - if not all - of the available bridging opportunities would have to be captured early on by the incumbent brokers. Empirically, however, this possibility is hardly supported in a large and sparse network such as ours, where only a fraction of potential ties is ever formed. Throughout the evolution of our partnership network, we found its global density to be consistently low and never higher than 5 percent of all possible ties. Similarly, the density of bridging ties within the main component (i.e., the count of actually formed bridging ties divided by all possible ties between clusters) 
never exceeded 1 percent. It is therefore hard to argue for a strong saturation effect emanating from the changing network architecture.

Our results also indicate that, in addition to the declining formation of bridging ties and the growing global separation that powerfully drives that decline, small worlds show a decline in local clustering. As our exploratory analyses indicated, this trend - which further reinforces the decline of the system's smallworldliness - is most likely driven by firms' decreasing propensity to form new local ties. While the decline in the formation of local ties was not as sharp as that in the formation of bridging ties, it is likely to have fostered sparse local neighborhoods, effectively creating a structure with low local interconnectivity. One possible explanation for this trend could be that as a social structure limits the flow of nonredundant knowledge, there is less and less need to create cohesive structural groups around transforming new knowledge into commercial applications. Not seeing any innovation benefits in external collaborations, organizations may become increasingly focused on internal innovation, foregoing the formation of both bridging and local ties altogether.

Our study makes several contributions to organizational theory. First, it adds to the broad literature on the social embeddedness of economic action (Granovetter 1985; Haunschild and Beckman 1998; Mizruchi 1992; Phillips and Zuckerman 2001). We show that underlying the market for interorganizational partnerships is a social structure shapes organizational behavior. The social structure we identify in this study has the topology of a small-world system, thereby reinforcing it as one of the most ubiquitous structural skeletons of social action. Acts of tie formation among organizations thus emerge not as atomistic market exchanges but rather as interdependent and socially embedded actions, the full implications of which can be understood only via careful consideration of the surrounding social context.

Second, we contribute to the growing body of research on the dynamics of social structure (e.g., Gulati 1995; Gulati and Gargiulo 1999; Powell et al. 2005) by exploring the micro-level dynamics associated with the emergence of social structure. We show that social structure should not be viewed as a static determinant of individual action, but rather as a vibrant and constantly evolving set of opportunities and constraints. Our findings suggest that at least in some systems, the recursive evolutionary cycle between the macro-level social structure and the formation of bridging ties at the micro level may take a social system through a set of dynamic equilibria that are jointly determined by collective benefits accruing to the system and by the distribution of 
individual rewards. In addition, this study takes a further step toward defining systematic phasal and temporal patterns in the evolution of social systems. Since our findings suggest that the complex evolutionary dynamics of social structures could drive substantial variation in actors' outcomes and behaviors over time, this research thus offers an impetus for future work on the temporally bounded effects of social structures (e.g., Mizruchi et al. 2006).

Third, our discussion shows that it is imperative to view complex social structures as multilevel systems in which evolutionary dynamics may be deeply intertwined over various levels of analysis and thus act in a tightly interdependent fashion. In doing so, we demonstrate the robustness of Coleman's (1990) view of the link between macro-social and micro-social levels of analysis, as well as Giddens's (1984) ideas on the duality of structure and action. We also fill an important lacuna in existing empirical studies by highlighting one set of recursive mechanisms through which a macro-level social structure elicits certain patterns of micro-level behavior, which in turn shape the very same macro structure. Finally, we contribute to studies of complex systems (e.g., Gell-Mann 1994; Waldrop 1992) by showing that the genesis and evolution of small worlds can be better understood by using an interdisciplinary approach that draws on the theories and methods of complex systems research. We show that small worlds are multi-level, open systems that can be characterized by nonlinear patterns of change and by not settling at an equilibrium. Rather, they constantly shift from one equilibrium to another, and each such dynamic equilibrium can be an entirely new small world that occurs in a vastly different region of the social network space and at a different time.

The complex nature of the evolution of small worlds, whose basic components we explore in this study, opens a broad array of opportunities for future research. First, we expect the dynamics highlighted in this study to progress into an even more complex pattern that subsequent studies can explore. These dynamics could be followed by a phase characterized by the continued decline of the system's small wordliness and a shrinking main component. Such a trend, however, would be accompanied by the development of an increasingly vibrant structure outside the main component of an existing small world. Not only is it conceivable that clusters located outside the main component would continue to grow, with one of them eventually overtaking the old core system and becoming the new main component; but it is also quite likely that this new main component would become more intricately connected internally and thus include both local and bridging ties. This condition of 
intricate connection might then lead to the emergence of a new small-world structure, making small worlds a transient but temporally recurrent feature of large social networks. At a higher level of analysis, this process could be described as a pulsating small-world network. Hints of this trend can be found in some of our results concerning the formation stage of small worlds, where we see the principal component not only acquire the properties of a small-world system but also rapidly grow in size by attracting multiple outside components that eventually become part of the complex internal structure of the growing small worlds. If our predictions about the pulsation of social networks are confirmed, then future research could explore the factors which explain why certain clusters lead the formation of a main component and hence the emergence of a small-world system. Examining these dynamics could offer interesting insights into possible coalitionary trends unfolding in networks as well as into global patterns of interdependence among organizations (Bae and Gargiulo 2004; Gulati and Sytch 2007). We see even further research potential in delving deeper into the actor-level dynamics underlying the evolution of small worlds (cf. Baum et al. 2003). Questions around which organizations enter into bridging ties, which organizations are among the first to leave a small world's deteriorating main component, and which organizations are among the first to take enter into bridging ties in new small worlds hold great theoretical value and great promise for future research.

\section{References}

Ahuja, G. 2000. Collaboration networks, structural holes, and innovation: A longitudinal study. Admi. Sci. Quart. 45(3) 425455.

Bae, J., M. Gargiulo. 2004. Partner substitutability, alliance network structure, and firm profitability in the telecommunications industry. Acad. of Management J. 47(6) 843-859.

Baker, W.E. 1984. The social structure of a national securities market. Amer. J. of Sociology 89(4) 775-811.

Baker, W.E., R.R. Faulkner. 2009. Social capital, double embeddedness, and mechanisms of stability and change. American Behavioral Scientist 52 1531-1555.

Barabási, A.-L., R. Albert. 1999. Emergence of scaling in random networks. Science 286 509-512.

Baron, R.M., D.A. Kenny. 1986. The moderator-mediator variable distinction in social psychological research: Conceptual, strategic, and statistical considerations. J. of Personality \& Social Psychology 51(6) 1173-1182.

Baum, J., R. Cowan, N. Jonard. 2009. Network-independent partner selection and the evolution of innovation networks. Working Paper, Presented at AOM 2009, Chicago.

Baum, J.A.C., T.J. Rowley, A.V. Shipilov, Y.-T. Chuang. 2005. Dancing with strangers: Aspiration performance and the search for underwriting syndicate partners. Admi. Sci. Quart. 50(4) 536-575.

Baum, J.A.C., A.V. Shipilov, T. Rowley. 2003. Where do small worlds come from? Industrial and Corporate Change 12(4) 697725.

Belsey, D.A., E. Kuh, R.E. Welsch. 1980. Regression Diagnostics: Identifying Influential Data and Sources of Collinearity. Wiley, New York.

Blau, P.M. 1964. Exchange and power in social life. John Wiley, New York.

Blau, P.M. 1977. A macrosociological theory of social structure. Amer. J. of Sociology 83(1) 26-54.

Brass, D.J. 1984. Being in the right place: A structural analysis of individual influence in an organization. Admi. Sci. Quart. 29 518-539. 
Bresnahan, T.F. 1999. New Modes of Competition: Implications for the Future Structure of the Computer Industry. T.M. Lenard, J.A. Eisenach, eds. Competition, Innovation and the Microsoft Monopoly: Antitrust in the Digital Marketplace. Kluwer, Norwell, MA, 155-209.

Bresnahan, T.F. 2000. Competition Cooperation, and Predation in Innovative Industries "Fighting Cartels - Why and How?" The 3RD Nordic Competition Policy Conference, Stockholm.

Bresnahan, T.F., S. Greenstein. 1999. Technological Competition and the Structure of the Computer Industry. J. of Industrial Economics 47 1-40.

Burt, R.S. 1992. Structural holes: The social structure of competition. Harvard University Press, Cambridge, MA.

Burt, R.S. 2004. Structural holes and good ideas. Amer. J. of Sociology 110 (2) 349-400.

Burt, R.S. 2005. Brokerage and Closure: An Introduction to Social Capital. Oxford University Press, New York.

Casciaro, T. 2003. Determinants of governance structures in alliances: The role of strategic, task, and partner uncertainties. Industrial and Corporate Change 12(6) 1223-1251.

Chesbrough, H.W. 2003. Open Innovation: The new imperative for creating and profiting from technology. Harvard Business School

Press, Boston, MA.

Clauset, A., C.R. Shalizi, M.E.J. Newman. 2009. Power-law distributions in empirical data. SLAM Review 51 661-703.

Coleman, J.S. 1990. Foundations of Social Theory. Harvard University Press, Cambridge, MA.

Cowan, R., N. Jonard. 2009. Knowledge portfolios and the organization of innovation networks. Acad.y of Management Rev. 34(2) 320-342.

Cowan, R., N. Jonard, J.-B. Zimmermann. 2007. Bilateral collaboration and the emergence of innovation networks.

Management Sci. 53(7) 1051-1067.

Datamonitor. 2006. Internet-based business: bubble trouble MarketWatch: Technology. Datamonitor.

Davis, G.F., H.R. Greve. 1997. Corporate elite networks and governance changes in the 1980s. Amer. J. of Sociology 103 1-37.

Davis, G.F., M. Yoo, W.E. Baker. 2003. The small world of the American corporate elite, 1982-2001. Strategic Organization

1(3) 301-326.

Davis, J.A. 1967. Clustering and structural balance in graphs. Human Relations 30 181-187.

Dedrick, J., K.L. Kraemer. 2005. The impacts of IT on firm and industry structure: The personal computer industry. California Management Rev. 47(3) 122-142.

Doreian, P., F. Stokman. 1997. The dynamics and evolution of social networks. P. Doreian, F. Stokman, eds. Evolution of Social Networks. G\&B Pubs, Amsterdam, 1-17.

Eisenhardt, K.M., B.N. Tabrizi. 1995. Accelerating adaptive processes: Product innovation in the global computer industry. Admi. Sci. Quart. 41(1) 84-100.

Emirbyaer, M., A. Mische. 1998. What is agency? Amer. J. of Sociology 103(4) 962-1023.

Fernandez, R.M., I. Fernandez-Mateo. 2006. Networks, race, and hiring. Amer. Sociological Rev. 71 42-71.

Galaskiewicz, J., W. Bielefeld, M. Dowell. 2006. Networks and organizational growth: A study of community based nonprofits. Admi. Sci. Quart. $51337-380$.

Garud, R., S. Jain, A. Kumaraswamy. 2002. Institutional entrepreneurship in the sponsorship of common technological standards: The case of Sun Microsystems and Java. Acad. of Management J. 45 196-214.

Gell-Mann, M. 1994. The Quark and the Jaguar: Adventures in the Simple and the Complex. W.H. Freeman, New York.

Giddens, A. 1984. The Constitution of Society: Outline of the Theory of Structure. University of California Press, Berkeley, CA.

Girvan, M., M.E.J. Newman. 2002. Community structure in social and biological networks. PNAS 99 7821-7826.

Granovetter, M. 1982. The strength of weak ties: A network theory revisted. P.V. Marsden, N. Lin, eds. Social structure and network analysis. Sage Publications, London, 105-131.

Granovetter, M. 1985. Economic action and social structure: The problem of embeddedness. Amer. J. of Sociology 91(3) 481510 .

Greif, A. 1993. Contract Enforceability and Economic Institutions in Early Trade: The Maghribi Traders' Coalition. Amer. Economic Rev. 83 99-118.

Grove, A. 1996. Only the Paranoid Survive. HarperCollins Business, New York.

Guimerà, R., L.A.N. Amaral. 2005. Functional cartography of complex metabolic networks. Nature 433 895-900.

Gulati, R. 1995. Social structure and alliance formation patterns: A longitudinal analysis. Admi. Sci. Quart. 40(4) 619-652.

Gulati, R. 1999. Network location and learning: The influence of network resources and firm capabilities on alliance formation. Strat. Management J. 20(5) 397-420.

Gulati, R., M. Gargiulo. 1999. Where do interorganizational networks come from? Amer. J. of Sociology 104(5) 1439-1493.

Gulati, R., M. Sytch. 2007. Dependence asymmetry and joint dependence in interorganizational relationships: Effects of embeddedness on exchange performance. Admi. Sci. Quart. 52 32-69.

Hall, B., A. Jaffe, M. Trajtenerg. 2001. The NBER Patent citation data file: Lessons, insights, and methodological tools. National Bureau of Economic Research.

Haunschild, P.R., C. Beckman. 1998. When do interlocks matter?: Alternate sources of information and interlock influence. Admi. Sci. Quart. 43(4) 815-844. 
Hilbe, J.M. 2007. Negative Binomial Regression. Cambridge University Press, Cambridge, UK.

Jackson, M.O., B.W. Rogers. 2007. Meeting strangers and friends of friends: How random are social networks? Ameri. Econ. Review 97(3) 890-915

Jaffe, A., M. Trajtenberg. 2002. Patents, citations, and innovations. MIT Press, Cambridge, MA.

Johnson, S.C. 1967. Hierarchical clustering schemes. Psychometrika 2 241-254.

Karinthy, F. 1929. Chains Everything is Different, Budapest.

Kogut, B., G. Walker. 2001. The small world of Germany and the durability of national networks. Amer. Sociological Rev. 66 317-335.

Kossinets, G. 2006. Effects of missing data in social networks. Social Networks 28 247-268.

Larson, A. 1992. Network dyads in entrepreneurial settings: A study of the governance of exchange relationships. Admi. Sci. Quart. 37(1) 76-104.

Lavie, D., L. Rosenkopf. 2006. Balancing exploration and exploitation in alliance formation. Acad. of Management J. 49(4) 797818.

Lazer, D., A. Friedman. 2007. The network structure of exploration and exploitation. Admi. Sci. Quart. 52 667-694.

Li, S.X., T.J. Rowley. 2002. Inertia and evaluation mechanisms in interorganizational partner selection: Syndicate formation among U.S. investment banks. Acad. of Management J. 45(6) 1104-1118.

Lin, N. 2001. Social Capital: A Theory of Social Structure and Action Cambridge University Press, Cambridge.

Madhavan, R., B.R. Koka, J.E. Prescott. 1998. Networks in transition: How industry events (re)shape interfirm relationships.

Strat. Management J. 19 439-459.

Malerba, F., L. Orsenigo. 1996. The Dynamics and Evolution of Industries. Industrial and Corporate Change(5) 51-87.

Marsden, P.V., N.E. Friedkin. 1993. Network studies of social influence. Sociological Methods Research 22 127-151.

McEvily, B., A. Zaheer. 1999. Bridging ties: A source of firm heterogeneity in competitive capabilities. Strat. Management J. 20(12) 1133-1156.

McPherson, J.M., L. Smith-Lovin, J.M. Cook. 2001. Birds of a feather: Homophily in social networks. Annual Rev. of Sociology 27 415-444.

Mizruchi, M.S. 1992. The Structure of Corporate Political Action: Interfirm Relations and Their Consequences. Harvard University Press, Cambridge, MA.

Mizruchi, M.S., L.B. Stearns, C. Marquis. 2006. The Conditional Nature of Embeddedness: A Study of Borrowing by Large U.S. Firms, 1973-1994. Amer. Sociological Rev. 71 310-333.

Newman, M.E.J. 2001. The structure of scientific collaboration networks. PNAS 98 404-409.

Newman, M.E.J. 2002. Assortative mixing in networks. Physical Rev. Letters 89208701.

Newman, M.E.J. 2004. Detecting community structure in networks. European Physical J. B 38 321-330.

Newman, M.E.J., M. Girvan. 2004. Finding and evaluating community structure in networks. Physical Rev. E 69026113.

Owen-Smith, J., W.W. Powell. 2004. Knowledge networks in the Boston biotechnology community. Org. Sci. 15(1) 5-21.

Ozcan, P., K.M. Eisenhardt. 2009. Origin of alliance portfolios: entrepreneurs, network srategies, and firm performance.

Acad. of Management J. 52(2) 246-279.

Perkins, A.B., M.C. Perkins. 2001. The Internet bubble: the inside story on why it burst and what you can do to profit now.

HarperBusiness, New York.

Phillips, D.J., E.W. Zuckerman. 2001. Middle-status conformity: Theoretical restatement and empirical demonstration in two markets. Amer. J. of Sociology 107 379-429.

Pimentel, B. 2003. Dell says some tech firms doomed San Francisco Chronicle, B1.

Podolny, J. 2001. Networks as the pipes and prisms of the market. Amer. J. of Sociology 107(1) 33-60.

Porac, J.F., H. Thomas, F. Wilson, D. Paton, A. Kanfer. 1995. Rivalry and the industry model of Scottish knitwear producers. Admi. Sci. Quart. 40 203-227.

Powell, W.W., K.W. Koput, L. Smith-Doerr. 1996. Interorganizational Collaboration and the Locus of Innovation:

Networks of Learning in Biotechnology. Admi. Sci. Quart. 41 116-145.

Powell, W.W., D.R. White, K.W. Koput, J. Owen-Smith. 2005. Network dynamics and field evolution: The growth of interorganizational collaboration in the life sciences. Amer. J. of Sociology 110(4) 1132-1205.

Richtel, M. 2000. Signs of market saturation in PC World New York Times, C8.

Riolli-Staltzman, L., F. Luthans. 2001. After the bubble burst: How small high-tech firms can keep in front of the wave. Acad. of Management Executive 15 114-124.

Rosenkopf, L., A. Metiu, V.P. George. 2001. From the bottom up? Technical committee activity and alliance formation. Admi. Sci. Quart. 46(4) 748-772.

Rosenkopf, L., M. Schilling. 2007. Comparing alliance network structure across industries: Observations and explanations. Strat. Entrepreneurship J. 1 191-209.

Rosenkopf, L., M. Tushman. 1998. The coevolution of community networks and technology: Lessons from the flight simulation industry. Industrial and Corporate Change 311-346. 
Roussos, G. 2005. Ubiquitous and Pervasive Computing: New Frontiers for Electronic Business, Computer Communications and Networks. Springer, Berlin.

Rowley, T., D. Behrens, D. Krackhardt. 2000. Redundant governance structures: An analysis of structural and relational embeddedness in the steel and semiconductor industries. Strat. Management J. 21(3) 369-386.

Schilling, M. 2009. Understanding alliance data. Strat. Management J. 30(3) 233-260.

Sewell, W.H. 1992. A theory of structure: Duality, agency, and transformation. Amer. J. of Sociology 98 1-29.

Shannon, C.E. 1948. A mathematical theory of communication. Bell System Technical Journal July-October.

Shipilov, A.V., S.X. Li. 2008. To have a cake and eat it too? Structural holes' influence on status accumulation and market performance in collaborative networks. Admi. Sci. Quart. 53(1) 73-108.

Shipilov, A.V., S.X. Li. 2010. The missing link: The effect of customers on the formation of relationships among producers in the multiplex triads. Org. Sci.(This issue).

Sorenson, O., T.E. Stuart. 2001. Syndication Networks and the Spatial Distribution of Venture Capital Investments. Amer. J. of Sociology 106 1546-1586.

Stuart, T.E. 1998. Network positions and propensities to collaborate: An investigation of strategic alliance formation in a high-technology industry. Admi. Sci. Quart. 43(3) 668-698.

Stuart, T.E. 2000. Interorganizational alliances and the performance of firms: A study of growth and innovation rates in a high-technology industry. Strat. Management J. 21(8) 791-811.

Uzzi, B. 1996. The sources and consequences of embeddedness for economic performance of organizations: the network

effect. Amer. Soc. Rev. 61 674-698.

Uzzi, B., J. Spiro. 2005. Collaboration and creativity: The small world problem. Amer. J. of Sociology 111(2) 447-504.

Waldrop, M.M. 1992. Complexity: The Emerging Science at the Edge of Order and Chaos. Simon \& Schuster, New York.

Wang, L., E.J. Zajac. 2007. Alliance or acquisition? A dyadic perspective on interfirm resource combinations. Strat.

Management J. 28(13) 1291-1317.

Wasserman, S., K. Faust. 1994. Social Network Analysis: Methods and Applications. Cambridge University Press, Cambridge.

Watts, D.J. 1999. Networks, dynamics, and the small-world phenomenon. Amer. J. of Sociology 105 493-528.

Watts, D.J., S.H. Strogatz. 1998. Collective dynamics of small-world networks. Nature 393 440-442.

White, H.C. 1981. Where do markets come from? Amer. J. of Sociology 87 517-547.

Zaheer, A., G.G. Bell. 2005. Benefiting from network position: Firm capabilities, structural holes, and performance. Strat.

Management J. 26 809-825.

Zaheer, A., E. Hernandez, S. Banerjee. 2010. Prior alliances with targets and acquisition performance in knowledge-intensive industries. Org. Sci. Forthcoming.

Zaheer, A., G. Soda. 2009. Network evolution: The origins of structural holes. Admi. Sci. Quart. 54 1-31.

\section{Figures and Tables}

Fig. 1. Increasing and declining smallworldliness of the network.

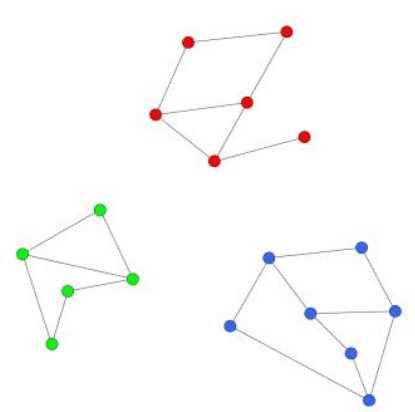

A

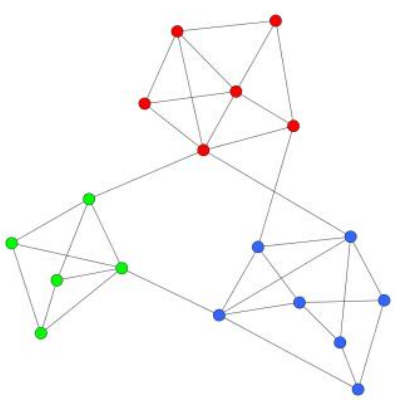

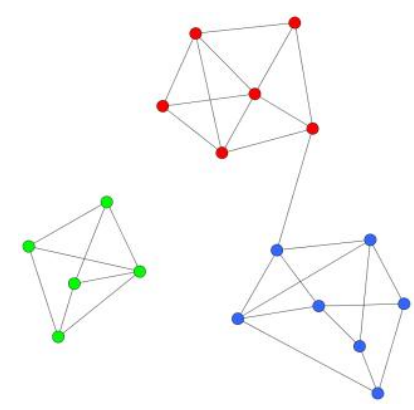

C 
Fig. 2a. Dynamics of clustering and avg. path length ratios.

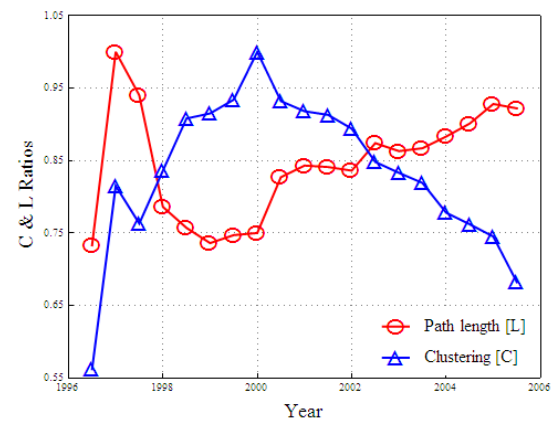

Fig. 3. New bridging ties per firm in the main component.

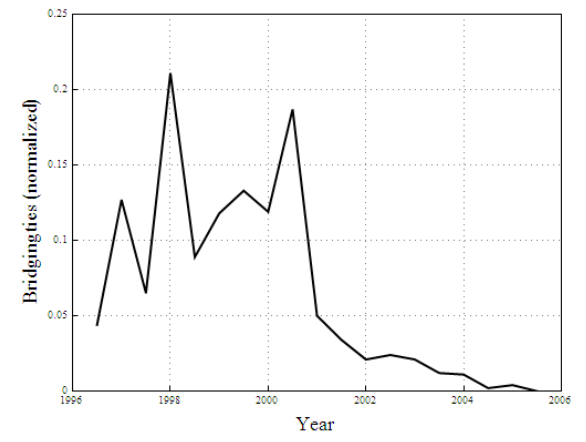

Fig. 5a. Industrial (SIC) diversity of firms in the small-world.

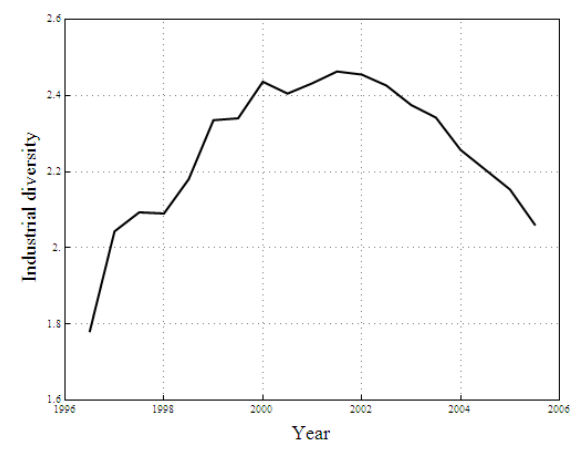

Fig. 6a. Relative number of network components.

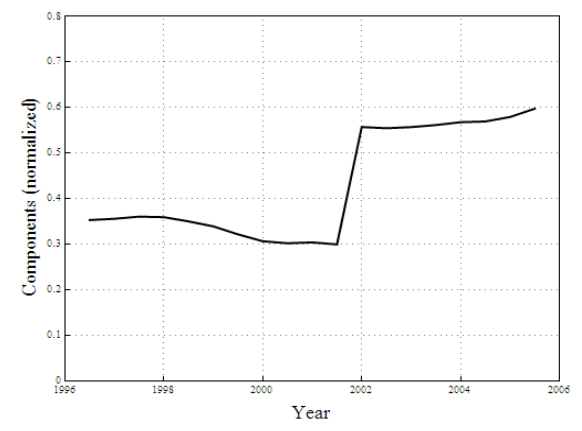

Fig. 2b. Dynamics of small-world quotient $(Q)$.

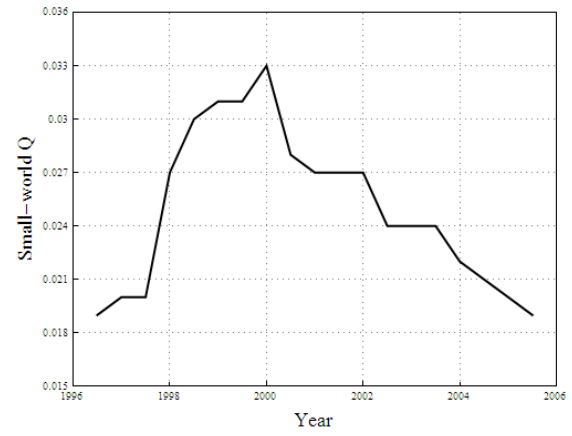

Fig. 4. New local ties per firm in the main component.

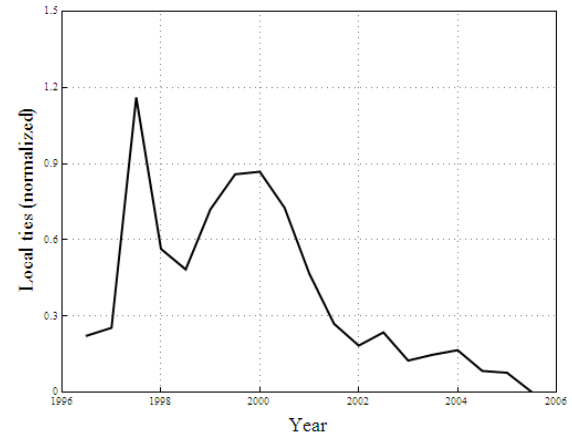

Fig. 5b. Technological (patent) diversity of firms in the small-world

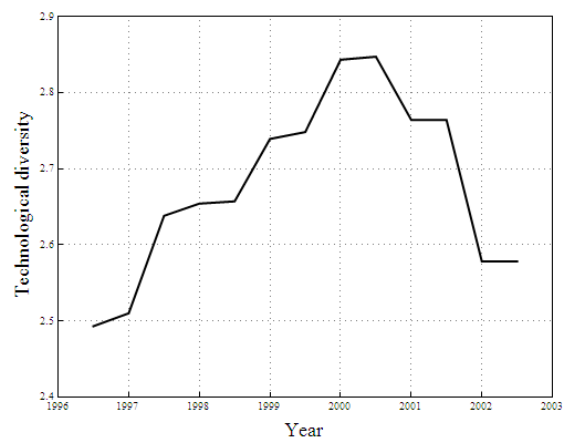

Fig. 6b. Location of newly formed ties

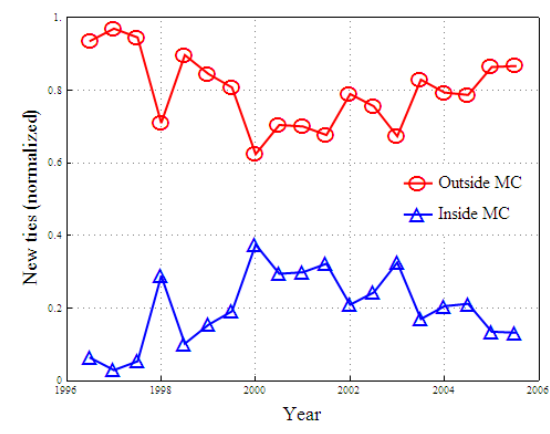


Table 1. Descriptive statistics and correlation matrix.

\begin{tabular}{|c|c|c|c|c|c|c|c|c|c|c|c|c|c|c|c|c|c|}
\hline & Variable name & Mean & SD & Min & $\operatorname{Max}$ & 1 & 2 & 3 & 4 & 5 & 6 & 7 & 8 & 9 & 10 & 11 & 12 \\
\hline$D V 1$ & Bridging ties & 0.036 & 0.368 & 0 & 15 & & & & & & & & & & & & \\
\hline DV2 & Local ties & 0.164 & 0.836 & 0 & 21 & & & & & & & & & & & & \\
\hline DV3 & Avg. path length & 2.796 & 2.163 & 1.000 & 12.619 & & & & & & & & & & & & \\
\hline DV4 & Clustering coefficient & 0.718 & 0.431 & 0.000 & 1.000 & & & & & & & & & & & & \\
\hline 1 & Profit margin & -0.918 & 10.842 & -360.833 & 8.434 & - & & & & & & & & & & & \\
\hline 2 & Debt ratio & 0.890 & 1.166 & 0.000 & 57.231 & -0.049 & - & & & & & & & & & & \\
\hline 3 & Headcount & 2.027 & 2.341 & 0.010 & 13.465 & 0.060 & 0.018 & - & & & & & & & & & \\
\hline 4 & SIC dummy 1 (group 35) & 0.096 & 0.295 & 0 & 1 & 0.001 & 0.021 & 0.039 & - & & & & & & & & \\
\hline 5 & SIC dummy 2 (group 36) & 0.113 & 0.316 & 0 & 1 & 0.010 & -0.035 & 0.086 & -0.116 & - & & & & & & & \\
\hline 6 & SIC dummy 3 (group 48) & 0.082 & 0.275 & 0 & 1 & -0.035 & 0.024 & 0.137 & -0.098 & -0.107 & - & & & & & & \\
\hline 7 & SIC dummy 4 (group 73) & 0.415 & 0.493 & 0 & 1 & -0.018 & -0.027 & -0.316 & -0.275 & -0.300 & -0.252 & - & & & & & \\
\hline 8 & SIC dummy 5 (other) & 0.294 & 0.455 & 0 & 1 & 0.033 & 0.025 & 0.174 & -0.210 & -0.230 & -0.193 & -0.543 & - & & & & \\
\hline 9 & Industrial similarity (DV1) & 0.015 & 0.034 & 0.000 & 1.000 & -0.012 & -0.013 & 0.047 & 0.145 & 0.068 & 0.025 & -0.100 & -0.047 & - & & & \\
\hline 10 & Industrial similarity (DV2) & 0.091 & 0.146 & 0.000 & 4.714 & -0.008 & -0.016 & 0.045 & 0.253 & 0.215 & -0.036 & -0.148 & -0.131 & 0.359 & - & & \\
\hline 11 & Industrial similarity (DV3) & 2.088 & 0.703 & 0.000 & 4.988 & 0.000 & 0.003 & 0.024 & 0.059 & -0.011 & 0.119 & -0.088 & -0.008 & 0.152 & 0.069 & - & \\
\hline 12 & Industrial similarity (DV4) & 0.808 & 0.222 & 0.000 & 1.000 & 0.004 & -0.009 & 0.052 & -0.044 & 0.002 & -0.026 & -0.076 & 0.125 & 0.164 & 0.080 & 0.716 & - \\
\hline 13 & Degree centrality & 1.073 & 0.597 & 0.693 & 4.443 & 0.038 & -0.002 & 0.216 & 0.078 & 0.056 & 0.018 & -0.023 & -0.076 & 0.026 & 0.026 & 0.054 & -0.011 \\
\hline 14 & Past partnership frequency & 1.114 & 0.648 & 0 & 4.868 & 0.022 & 0.005 & 0.184 & 0.110 & 0.074 & -0.022 & -0.041 & -0.065 & 0.015 & 0.033 & 0.018 & -0.034 \\
\hline 15 & Firm inside $\mathrm{MC}$ & 0.363 & 0.481 & 0 & 1 & -0.017 & -0.042 & 0.033 & -0.022 & -0.007 & -0.007 & 0.010 & 0.012 & 0.362 & 0.369 & 0.176 & 0.308 \\
\hline 16 & Ties outside MC & 112.196 & 62.493 & 13 & 284 & 0.023 & -0.024 & 0.110 & 0.038 & 0.032 & 0.047 & -0.014 & -0.060 & -0.019 & -0.001 & 0.088 & -0.062 \\
\hline 17 & Post inflection & 0.802 & 0.399 & 0 & 1 & 0.003 & 0.000 & -0.094 & -0.094 & -0.062 & -0.009 & 0.044 & 0.061 & -0.119 & -0.125 & 0.288 & -0.164 \\
\hline 18 & Local ties & 0.165 & 0.841 & 0 & 21 & 0.013 & -0.005 & 0.089 & 0.052 & 0.029 & -0.011 & -0.007 & -0.039 & 0.170 & 0.090 & 0.027 & 0.030 \\
\hline 19 & Bridging ties & 0.036 & 0.368 & 0 & 15 & 0.008 & 0.001 & 0.079 & 0.058 & 0.045 & -0.017 & -0.019 & -0.037 & 0.062 & 0.153 & 0.016 & 0.015 \\
\hline & & & & & & 13 & 14 & 15 & 16 & 17 & 18 & 19 & & & & & \\
\hline 13 & Degree centrality & & & & & - & & & & & & & & & & & \\
\hline 14 & Past partnership frequency & & & & & 0.749 & - & & & & & & & & & & \\
\hline 15 & Firm inside MC & & & & & -0.016 & -0.019 & - & & & & & & & & & \\
\hline 16 & Ties outside MC & & & & & 0.448 & 0.290 & -0.058 & - & & & & & & & & \\
\hline 17 & Post inflection & & & & & 0.041 & 0.037 & 0.077 & 0.165 & - & & & & & & & \\
\hline 18 & Local ties & & & & & 0.395 & 0.411 & 0.083 & 0.260 & -0.012 & - & & & & & & \\
\hline 19 & Bridging ties & & & & & 0.331 & 0.465 & 0.076 & 0.131 & -0.012 & 0.413 & - & & & & & \\
\hline
\end{tabular}


Table 2. Statistical modeling of attachment (Models 1-2: Negative binomial regression; Models 3-8: OLS regression).

\begin{tabular}{|c|c|c|c|c|c|c|c|c|}
\hline DV & $\begin{array}{l}\text { Model } 1 \\
\text { Bridging ties }\end{array}$ & $\begin{array}{c}\text { Model } 2 \\
\text { Local ties }\end{array}$ & $\begin{array}{c}\text { Model } 3 \\
\text { Avg. path length }\end{array}$ & $\begin{array}{c}\text { Model } 4 \\
\text { Clustering coefficient }\end{array}$ & $\begin{array}{c}\text { Model } 5 \\
\text { Avg. path length }\end{array}$ & $\begin{array}{c}\text { Model } 6 \\
\text { Clustering coefficient }\end{array}$ & $\begin{array}{c}\text { Model } 7 \\
\text { Avg. path length }\end{array}$ & $\begin{array}{c}\text { Model } 8 \\
\text { Clustering coefficient }\end{array}$ \\
\hline Constant & $\begin{array}{l}-8.1252 \\
(0.3272)^{* * *}\end{array}$ & $\begin{array}{l}-4.7761 \\
(0.1403)^{* * *}\end{array}$ & $\begin{array}{l}1.4017 \\
(0.0681)^{* * *}\end{array}$ & $\begin{array}{l}1.3512 \\
(0.0247)^{* * *}\end{array}$ & $\begin{array}{l}1.3761 \\
(0.0679)^{* * *}\end{array}$ & $\begin{array}{l}1.3554 \\
(0.0247)^{* * *}\end{array}$ & $\begin{array}{l}1.3802 \\
(0.0680)^{* * *}\end{array}$ & $\begin{array}{l}1.3548 \\
(0.0247)^{* * *}\end{array}$ \\
\hline Profit margin & $\begin{array}{l}0.0108 \\
(0.0231)\end{array}$ & $\begin{array}{l}0.0208 \\
(0.0151)\end{array}$ & $\begin{array}{l}0.0002 \\
(0.0014)\end{array}$ & $\begin{array}{l}-0.0003 \\
(0.0002)\end{array}$ & $\begin{array}{l}0.0002 \\
(0.0014)\end{array}$ & $\begin{array}{l}-0.0003 \\
(0.0002)\end{array}$ & $\begin{array}{l}0.0002 \\
(0.0014)\end{array}$ & $\begin{array}{l}-0.0003 \\
(0.0002)\end{array}$ \\
\hline Debt ratio & $\begin{array}{l}0.0786 \\
(0.0159)^{* * *}\end{array}$ & $\begin{array}{l}-0.0040 \\
(0.0487)\end{array}$ & $\begin{array}{l}-0.0061 \\
(0.0120)\end{array}$ & $\begin{array}{l}0.0098 \\
(0.0048)^{* *}\end{array}$ & $\begin{array}{l}-0.0059 \\
(0.0120)\end{array}$ & $\begin{array}{l}0.0097 \\
(0.0048)^{* *}\end{array}$ & $\begin{array}{l}-0.0061 \\
(0.0120)\end{array}$ & $\begin{array}{l}0.0098 \\
(0.0048) * *\end{array}$ \\
\hline Headcount & $\begin{array}{l}-0.0019 \\
(0.0333)\end{array}$ & $\begin{array}{l}0.0126 \\
(0.0170)\end{array}$ & $\begin{array}{l}0.0034 \\
(0.0073)\end{array}$ & $\begin{array}{l}0.0060 \\
(0.0031)^{*}\end{array}$ & $\begin{array}{l}0.0028 \\
(0.0073)\end{array}$ & $\begin{array}{l}0.0061 \\
(0.0031)^{*}\end{array}$ & $\begin{array}{l}0.0028 \\
(0.0073)\end{array}$ & $\begin{array}{l}0.0061 \\
(0.0031)^{*}\end{array}$ \\
\hline SIC group dummies & Yes & Yes & Yes & Yes & Yes & Yes & Yes & Yes \\
\hline Network autocorrelation & $\begin{array}{l}6.8897 \\
(1.6276)^{* * *}\end{array}$ & $\begin{array}{l}1.3432 \\
(0.3310)^{* * *}\end{array}$ & $\begin{array}{l}0.0376 \\
(0.0182)^{* *}\end{array}$ & $\begin{array}{l}0.0365 \\
(0.0130)^{* * *}\end{array}$ & $\begin{array}{l}0.0381 \\
(0.0182)^{* *}\end{array}$ & $\begin{array}{l}0.0359 \\
(0.0130)^{* * *}\end{array}$ & $\begin{array}{l}0.0384 \\
(0.0182)^{* *}\end{array}$ & $\begin{array}{l}0.0360 \\
(0.0130)^{* * *}\end{array}$ \\
\hline Degree centrality & $\begin{array}{l}2.8586 \\
(0.1559)^{* * *}\end{array}$ & $\begin{array}{l}2.2787 \\
(0.0730)^{* * *}\end{array}$ & $\begin{array}{l}-0.0914 \\
(0.0571)\end{array}$ & $\begin{array}{l}-0.5346 \\
(0.0278)^{* * *}\end{array}$ & $\begin{array}{l}-0.0817 \\
(0.0561)\end{array}$ & $\begin{array}{l}-0.5379 \\
(0.0278)^{* * *}\end{array}$ & $\begin{array}{l}-0.0773 \\
(0.0558)\end{array}$ & $\begin{array}{l}-0.5385 \\
(0.0278)^{* * *}\end{array}$ \\
\hline Past partnership frequency & $\begin{array}{l}-0.0312 \\
(0.0040)^{* * *}\end{array}$ & $\begin{array}{l}-0.0344 \\
(0.0031)^{* * *}\end{array}$ & $\begin{array}{l}-0.0216 \\
(0.0034) * * *\end{array}$ & $\begin{array}{l}0.0142 \\
(0.0019)^{* * *}\end{array}$ & $\begin{array}{l}-0.0165 \\
(0.0031)^{* * *}\end{array}$ & $\begin{array}{l}0.0141 \\
(0.0019)^{* * *}\end{array}$ & $\begin{array}{l}-0.0170 \\
(0.0031)^{* * *}\end{array}$ & $\begin{array}{l}0.0141 \\
(0.0019)^{* * *}\end{array}$ \\
\hline Firm inside MC & $\begin{array}{l}-0.3413 \\
(0.2428)\end{array}$ & $\begin{array}{l}-0.7526 \\
(0.0992)^{* * *}\end{array}$ & $\begin{array}{l}3.7323 \\
(0.0443)^{* * *}\end{array}$ & $\begin{array}{l}-0.0383 \\
(0.0161)^{* *}\end{array}$ & $\begin{array}{l}3.7516 \\
(0.0448)^{* * *}\end{array}$ & $\begin{array}{l}-0.0420 \\
(0.0161)^{* * *}\end{array}$ & $\begin{array}{l}3.7520 \\
(0.0448)^{* * *}\end{array}$ & $\begin{array}{l}-0.0420 \\
(0.0161)^{* * *}\end{array}$ \\
\hline Ties outside MC & - & - & $\begin{array}{l}0.0003 \\
(0.0002)\end{array}$ & $\begin{array}{l}0.0001 \\
(0.0001)\end{array}$ & $\begin{array}{l}0.0005 \\
(0.0002)^{* *}\end{array}$ & $\begin{array}{l}0.0001 \\
(0.0001)\end{array}$ & $\begin{array}{l}0.0005 \\
(0.0002) * *\end{array}$ & $\begin{array}{l}0.0001 \\
(0.0001)\end{array}$ \\
\hline Post inflection & $\begin{array}{l}-0.8269 \\
(0.1732)^{* * *}\end{array}$ & $\begin{array}{l}-0.6104 \\
(0.0786) * * *\end{array}$ & $\begin{array}{l}0.1770 \\
(0.0364)^{* * *}\end{array}$ & $\begin{array}{l}-0.0641 \\
(0.0139)^{* * *}\end{array}$ & $\begin{array}{l}0.1630 \\
(0.0366)^{* * *}\end{array}$ & $\begin{array}{l}-0.0626 \\
(0.0141)^{* * *}\end{array}$ & $\begin{array}{l}0.1543 \\
(0.0366) * * *\end{array}$ & $\begin{array}{l}-0.0615 \\
(0.0141)^{* * *}\end{array}$ \\
\hline Local ties & & & & & $\begin{array}{l}-0.0728 \\
(0.0107)^{* * *}\end{array}$ & $\begin{array}{l}0.0162 \\
(0.0036)^{* * *}\end{array}$ & $\begin{array}{l}-0.0694 \\
(0.0103)^{* * *}\end{array}$ & $\begin{array}{l}0.0157 \\
(0.0036) * * *\end{array}$ \\
\hline Bridging ties & & & & & $\begin{array}{l}-0.1230 \\
(0.0337)^{* * *}\end{array}$ & $\begin{array}{l}-0.0129 \\
(0.0086)\end{array}$ & $\begin{array}{l}-0.2915 \\
(0.0493)^{* * *}\end{array}$ & $\begin{array}{l}0.0073 \\
(0.0158)\end{array}$ \\
\hline Bridging ties $\times$ Post inflection & & & & & & & $\begin{array}{l}0.2101 \\
(0.0523)^{* * *}\end{array}$ & $\begin{array}{l}-0.0252 \\
(0.0149)\end{array}$ \\
\hline Log-likelihood & $-1168.0^{* * *}$ & $-4720.4^{* * *}$ & - & - & - & - & - & - \\
\hline R-squared & - & - & 0.65 & 0.40 & 0.66 & 0.40 & 0.66 & 0.40 \\
\hline Obs. & 14550 & 14550 & 14550 & 14550 & 14550 & 14550 & 14550 & 14550 \\
\hline
\end{tabular}

Standard errors in parentheses; ${ }^{* *} p<.01,{ }^{* *} p<.05,{ }^{*} p<.10$ 